\title{
BET protein inhibitor apabetalone (RVX-208) suppresses pro-inflammatory hyper-activation of monocytes from patients with cardiovascular disease and type 2 diabetes
}

Sylwia Wasiak ${ }^{1 \dagger}$, Kim E. Dzobo ${ }^{2}$, Brooke D. Rakai ${ }^{1}$, Yannick Kaiser ${ }^{3}$, Miranda Versloot ${ }^{2}$, Mahnoush Bahjat ${ }^{2}$, Stephanie C. Stotz ${ }^{1}$, Li Fu', Michael Sweeney ${ }^{1}$, Jan O. Johansson ${ }^{1}$, Norman C. W. Wong ${ }^{1}$, Erik S. G. Stroes ${ }^{3}$, Jeffrey Kroon ${ }^{2+}$ and Ewelina Kulikowski ${ }^{1 *+}+0$

\begin{abstract}
Background: Patients with cardiovascular disease (CVD) and type 2 diabetes (DM2) have a high residual risk for experiencing a major adverse cardiac event. Dysregulation of epigenetic mechanisms of gene transcription in innate immune cells contributes to CVD development but is currently not targeted by therapies. Apabetalone (RVX-208) is a small molecule inhibitor of bromodomain and extra-terminal (BET) proteins-histone acetylation readers that drive pro-inflammatory and pro-atherosclerotic gene transcription. Here, we assess the impact of apabetalone on ex vivo inflammatory responses of monocytes from DM2 + CVD patients.

Results: Monocytes isolated from DM2 + CVD patients and matched controls were treated ex vivo with apabetalone, interferon $\gamma$ (IFNY), IFNY + apabetalone or vehicle and phenotyped for gene expression and protein secretion. Unstimulated DM2 + CVD monocytes had higher baseline IL-1 a, IL-1 $\beta$ and IL-8 cytokine gene expression and Tolllike receptor (TLR) 2 surface abundance than control monocytes, indicating pro-inflammatory activation. Further, $\mathrm{DM} 2+\mathrm{CVD}$ monocytes were hyper-responsive to stimulation with IFNy, upregulating genes within cytokine and NF-kB pathways $>30 \%$ more than control monocytes $(p<0.05)$. Ex vivo apabetalone treatment countered cytokine secretion by DM2 + CVD monocytes at baseline (GROa and IL-8) and during IFNy stimulation (IL-1 $\beta$ and TNFa). Apabetalone abolished pro-inflammatory hyper-activation by reducing TLR and cytokine gene signatures more robustly in $\mathrm{DM} 2+\mathrm{CVD}$ versus control monocytes.
\end{abstract}

Conclusions: Monocytes isolated from DM2 + CVD patients receiving standard of care therapies are in a hyperinflammatory state and hyperactive upon IFNy stimulation. Apabetalone treatment diminishes this pro-inflammatory phenotype, providing mechanistic insight into how BET protein inhibition may reduce CVD risk in DM2 patients.

Keywords: Bromodomain, Transcription regulation, Innate immune response, Cardiovascular, Apabetalone

*Correspondence: Ewelina@resverlogix.com

†Sylwia Wasiak and Kim E. Dzobo are co-first authors

${ }^{\dagger} J$ Jeffrey Kroon and Ewelina Kulikowski are co-senior authors

${ }^{1}$ Resverlogix Corp, 300-4820 Richard Road SW, Calgary, AB T3E 6L1, Canada

Full list of author information is available at the end of the article

\section{Background}

Low-density lipoprotein cholesterol (LDL-C) lowering is the key strategy to prevent cardiovascular disease (CVD). However, even a substantial reduction in LDL-C still leaves patients at a significant residual risk of cardiovascular adverse events. Amongst others, type 2 diabetes 
mellitus (DM2) is recognized as a contributor to CVD risk [1]. This comorbidity is likely caused by organ exposure to chronic systemic low-grade inflammation caused by elevated circulating levels of cytokines IL- 6 and IL-1 $\beta$, glucose, free fatty acids and reactive oxygen species (ROS) [2-6]. Such a microenvironment favours monocyte infiltration into the arterial wall, where these cells differentiate into macrophages that contribute to initiation and progression of atherosclerosis. Ultimately, macrophage activity in atherosclerotic plaque precipitates atherothrombosis and clinical cardiovascular events [7].

Monocyte activity is not restricted to the arterial wall as circulating monocytes are also a major source of proinflammatory and pro-oxidant factors [7]. In fact, monocytes from patients with advanced atherosclerosis and/or hypercholesterolemia are hyper-responsive and therefore produce more pro-inflammatory cytokines, such as interleukin (IL) 6, IL-1 $\beta$ and TNF $\alpha$ [8-10]. This pro-inflammatory state is partially ascribed to hypercholesterolemia, which reprograms myeloid progenitors in the bone marrow to produce hyperactive monocytes and macrophages in experimental atherosclerosis models [11-13]. The resulting "immunological memory" is encoded by epigenetic changes to chromatin in the form of DNA methylation and histone post-translational modification [14]. The contribution of histone marks to persistent immune cell activation has been demonstrated in atherosclerotic mouse models $[15,16]$, in human monocytes isolated from DM2 and CVD patients' blood or from atherosclerotic plaques $[9,10,17-19]$. This evidence of widespread epigenetic dysregulation in activated immune cells opens the window for epigenetic regulators as therapeutic agents in DM2 and CVD [14].

Bromodomain and extraterminal (BET) proteins (BRD2, BRD3, BRD4 and BRDT) are histone acetylation "readers" generally linked to the induction of gene transcription [20]. BET proteins are recruited to gene enhancers and promoters via direct binding to acetylated chromatin or to acetylated transcription factors, such as the nuclear factor $\mathrm{k}$-light-chain-enhancer of activated $\mathrm{B}$ cells $(\mathrm{NF}-\mathrm{kB})$ and the signal transducer and activator of transcription (STAT) [21-25]. Once chromatin-bound, BETs recruit chromatin remodeling and transcription elongation factors, leading to activation of RNA polymerase II and transcription of proximal genes [26]. Since BET proteins play a critical role in transcription of cytokine response genes involved in inflammation, lipid metabolism and vascular function [23, 27-30], inhibiting their activity could prove beneficial for the treatment of chronic inflammatory and metabolic diseases.

Apabetalone (RVX-208) is an orally available small molecule BET inhibitor (BETi) that mimics the endogenous ligand of BET proteins, the acetylated lysine residue.
Apabetalone preferentially binds to the second of two conserved BET protein bromodomains (with $>20$-fold higher affinity) [31-33], countering BET protein recruitment to chromatin. Consequently, apabetalone inhibits transcription of BET-dependent genes [31, 34]. In vitro treatment with apabetalone reduces pro-inflammatory gene expression in cellular models of atherosclerosis, including endothelial cells [34, 35], monocytes [34] and vascular smooth muscle cells [36]. Apabetalone also reduces vascular inflammation and atherosclerosis in mouse models [23,35]. These data suggest that apabetalone could correct the pro-inflammatory phenotype of innate immune cells characteristic of DM2 and CVD.

Here, we demonstrate that monocytes isolated from patients with DM2 and CVD (DM2 + CVD) have an enhanced pro-inflammatory phenotype as compared to matched controls. Moreover, challenging DM2 + CVD monocytes ex vivo with interferon gamma (IFNY), a key cytokine that triggers monocyte differentiation into the pro-inflammatory macrophage M1 subtype [37], provokes a hyperactive transcriptional response as compared to controls. Ex vivo apabetalone treatment diminishes this hyper-inflammatory state, suggesting that BET protein inhibition can mitigate monocyte-driven inflammation in patients with high residual risk for major adverse cardiovascular events.

\section{Results \\ Apabetalone suppresses pro-inflammatory cytokine secretion in monocytes from DM2 + CVD patients}

For this study, we recruited patients with DM2 and stable CVD (DM2+CVD) $(n=14)$, and age- and gendermatched control subjects $(n=12)$ (Table 1). DM2 + CVD patients, on standard of care including insulin and/ or statins, had higher glucose levels (mean 8.05, [7.3010.15]) than controls (mean 5.35, [5.20-5.60]). They also had increased systolic blood pressure (142.93 (13.38)), elevated triglycerides levels (1.39, [1.13-1.70]), and reduced HDL levels $(1.31(0.22))$. Control subjects were not on any medication.

Monocytes were isolated from whole blood of patients with DM2 + CVD or matched control subjects. Total monocyte number (Table 1) and distribution across subset classifications (Additional file 1) were similar in both cohorts. Profiling of 16 monocyte surface receptors revealed higher expression of Toll-like receptor (TLR) 2 on intermediate $\left(\mathrm{CD} 14^{++} \mathrm{CD} 16^{+}\right)$and non-classical $\left(\mathrm{CD} 14^{+} \mathrm{CD} 16^{+}\right)$DM2 + CVD monocytes $(n=14)$ as compared to controls $(n=12)$ (Fig. 1a), consistent with published observations [38-40]. No change in TLR2 abundance was noted in the total or classical monocyte population (Fig. 1a). 
Table 1 Baseline clinical characteristics of enrolled subjects

\begin{tabular}{|c|c|c|c|}
\hline Clinical characteristics & $\mathrm{DM} 2+\mathrm{CVD}(n=14)$ & Controls $(n=12)$ & $p$ value \\
\hline Age & $68.39(5.08)$ & $68.09(5.16)$ & 0.9 \\
\hline Gender (male \%) & $7(50)$ & $8(66.7)$ & 0.7 \\
\hline BMI (mean (SD)) & $31.06(6.85)$ & $26.71(5.66)$ & 0.09 \\
\hline \multicolumn{4}{|l|}{ Lifestyle } \\
\hline Current smoker & $0(0)$ & $0(0)$ & 1 \\
\hline Former smoker & $7(50)$ & $6(50.0)$ & 1 \\
\hline Past smoker & $7(50)$ & $6(50.0)$ & 1 \\
\hline Pack-years (mean (SD)) & $9.50[0-45]$ & $4.00[0-10.5]$ & 0.06 \\
\hline Systolic BP (mean (SD)) & $142.93(13.38)$ & $127.5(15.21)$ & 0.01 \\
\hline \multicolumn{4}{|l|}{ Medical history } \\
\hline AP $(\%)$ & $7(50)$ & $0(0)$ & 0.02 \\
\hline MI (\%) & $4(28.6)$ & $0(0)$ & 0.1 \\
\hline CVA (\%) & $2(14.3)$ & $0(0)$ & 0.5 \\
\hline PAD (\%) & $6(42.9)$ & $0(0)$ & 0.03 \\
\hline CRP (median [IQR]) & $1.50[1.30-3.15]$ & $1.35[0.85-2.02]$ & 0.3 \\
\hline Leukocytes (mean (SD)) & $6.59(1.35)$ & $5.57(1.65)$ & 0.1 \\
\hline Monocytes (mean (SD)) & $0.56(0.17)$ & $0.50(0.13)$ & 0.4 \\
\hline Glucose (median [IQR]) & $8,05[7.30-10.15]$ & $5.35[5.20-5.60]$ & $<0.001$ \\
\hline Creatinine (median [IQR]) & 89.5 [84-113.75] & 84.5 [66.5-92] & 0.08 \\
\hline Total cholesterol (mean (SD)) & $3.97(0.77)$ & $5.48(1.21)$ & 0.001 \\
\hline HDL cholesterol (mean (SD)) & $1.31(0.22)$ & $1.73(0.69)$ & 0.04 \\
\hline LDL cholesterol (mean (SD)) & $1.93(0.47)$ & $3.23(0.79)$ & $<0.001$ \\
\hline Triglycerides (median [IQR]) & $1.39[1.13-1.70]$ & $0.85[0.71-1.29]$ & 0.02 \\
\hline Lp(a) (median [IQR]) & $103[90-120.5]$ & 87.5 [45.25-148.75] & 0.9 \\
\hline Hba1c (median [IQR]) & $63[54.5-66.75]$ & 38.5 [38-39.25] & $<0.001$ \\
\hline Statin use (\%) & $12(85.7)$ & 0 & $<0.001$ \\
\hline Insulin use (\%) & $10(71.4)$ & 0 & 0.001 \\
\hline
\end{tabular}

Data are presented as the mean (SD), median (IQR) or $n$ (\%)

$B M I$ body mass index, $B P$ blood pressure, $A P$ angina pectoris, $M I$ myocardial infarction; $C V A$ cerebrovascular accident, $P A D$ peripheral arterial disease, $C R P C$-reactive protein, $H D L$ high-density lipoprotein, $L D L$ low-density lipoprotein; $L p(a)$ lipoprotein (a)

The multianalyte immunoprofiling Milliplex ${ }^{\circledR}$ panel detected 12 cytokines that were secreted by monocytes cultured ex vivo for $24 \mathrm{~h}$. At baseline, monocytes from DM2 + CVD patients $(n=14)$ showed higher levels of chemokine IL-8 (encoded by the CXCL8 gene), growthrelated oncogene- $\alpha$ (GRO- $\alpha$, encoded by the CXCL1 gene) and PDGF-AA, as compared to controls $(n=12)$ (Fig. 1b). Notably, apabetalone $(25 \mu \mathrm{M})$ lowered the enhanced secretion of IL-8 and GRO $\alpha$ in DM2 + CVD monocytes (Fig. 1b). Similarly, apabetalone decreased the secretion of monocyte chemoattractant protein 1 (MCP-1) (also detected by ELISA), MCP-3, granulocytemacrophage colony stimulating factor (GM-CSF) and interleukin 1 receptor antagonist IL-1RA) (Fig. 1c). Macrophage inflammatory protein MIP-1 $\alpha$ (CCL3) was the only protein whose secretion increased with apabetalone treatment (Fig. 1c); no changes were detected in CCL3 mRNA transcript levels (data not shown). IL-1 $\beta$, TNF $\alpha$, IP-10 and RANTES were not differentially secreted at baseline nor affected by apabetalone treatment (not shown). No toxicity was noted across all treatments and time points (Additional file 2). These data indicate that DM2 + CVD monocytes secreted higher levels of proinflammatory cytokines ex vivo, which was abolished by treatment with apabetalone.

\section{Apabetalone abolishes "hyperactive" gene expression in monocytes from DM2 + CVD patients}

The monocyte gene transcription profile was generated for DM2 + CVD monocytes $(n=8)$ and control monocytes $(n=9)$ using the NanoString nCounter ${ }^{\circledR}$ Vantage $3 \mathrm{D}^{\mathrm{TM}}$ Innate Immunity Panel $(0.025 \%$ DMSO, $4 \mathrm{~h}$ ). Transcripts for 109 of the 180 genes in the panel were detected (endogenous control-normalized counts $>50$ ) in at least one treatment condition. Between-cohort baseline comparison showed that mRNA transcripts encoding pro-inflammatory cytokines (IL1B, IL1A and CXCL8) and the receptor for the Fc region of IgA $(F C A R)$ were 


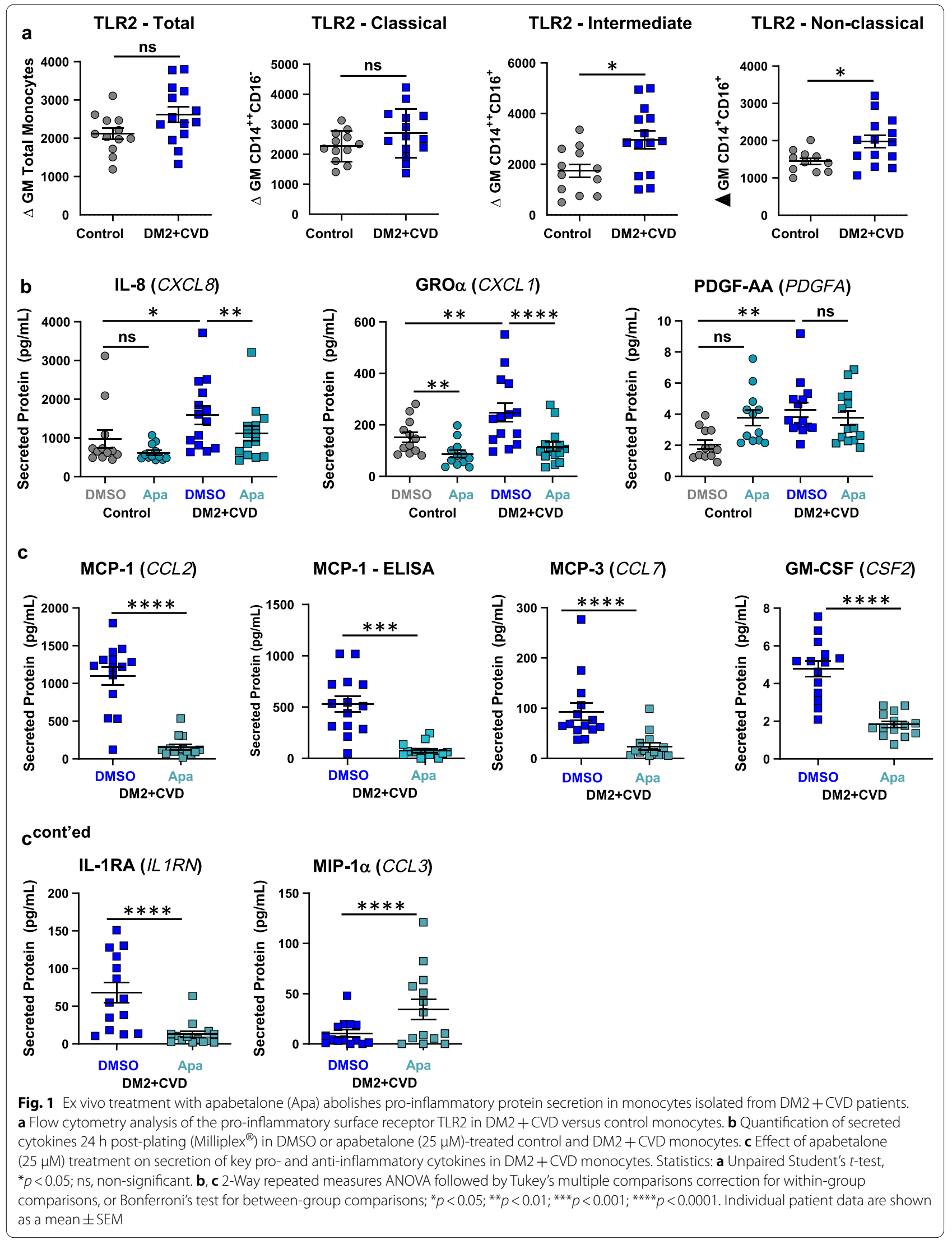


more abundant in monocytes from DM2 + CVD patients than controls (Fig. 2a). In contrast, transcripts encoding the macrophage receptor with collagenous structure (MARCO), the membrane-spanning 4-domains subfamily A member $4 \mathrm{~A}(M S 4 A 4 A)$ and the splicing factor $3 \mathrm{~A}$ subunit 3 (SF3A3) were lower in abundance in monocytes from DM2 +CVD patients. Collectively, these results indicate that the monocytes of DM2 +CVD patients exhibit a hyperactive pro-inflammatory transcriptional state.

To examine whether the hyperactive pro-inflammatory gene transcription can be diminished by BET inhibition, monocytes from patients and control subjects were treated ex vivo with apabetalone ( 5 or $25 \mu \mathrm{M})$ or DMSO (vehicle control) for $4 \mathrm{~h}$. With the exception of $I L 1 B$, mRNA transcripts overexpressed in DM2 + CVD monocytes (IL1A, CXCL8, FCAR) were downregulated by treatment with $25 \mu \mathrm{M}$ apabetalone (Fig. 2a). mRNA transcripts expressed at lower levels in DM2 + CVD monocytes versus controls (MARCO, MS4A4A and SF3A3) were further reduced by apabetalone (Fig. 2b). Transcription of $B R D 4$, the gene encoding the BRD4 BET protein, was also reduced by apabetalone (Additional file 3), while the abundance of $B R D 2$ or $B R D 3$ transcripts was unaltered (data not shown). A decrease in BRD4 levels could potentially reduce BET-dependent transcriptional regulation in monocytes.

Overall, treatment of DM2+CVD monocytes with $25 \mu \mathrm{M}$ apabetalone altered the abundance of 39 out of 109 transcripts detected by the NanoString Innate Immunity Panel $(>30 \%$ change with adjusted $\mathrm{p}<0.05)$ (Table 2). 36 of 39 transcripts were downregulated, whereas 3 of them were upregulated by apabetalone treatment (Table 2). Ten gene transcripts were also sensitive to $5 \mu \mathrm{M}$ apabetalone (marked by asterisks in Table 2). Gene transcription in control monocytes was similarly altered by apabetalone, but with several notable exceptions (Fig. 3a). Target genes associated with NF-kB pathway activation, including TANK-binding kinase 1 (TBK1) and IL-1 receptor-associated kinase 1 (IRAK1), as well as the NF- $\mathrm{kB}$ subunit 1 (NFKB1), were more efficiently suppressed by apabetalone in DM2 + CVD monocytes versus controls. Similarly, apabetalone differentially reduced gene expression of the phagocytic macrophage receptor CD68 [41], of the IL-10 receptor subunit IL10RB implicated in pro- and anti-inflammatory homeostasis [42], and of MTMR14 encoding a phosphoinositide phosphatase involved in metabolic dysregulation in obesity
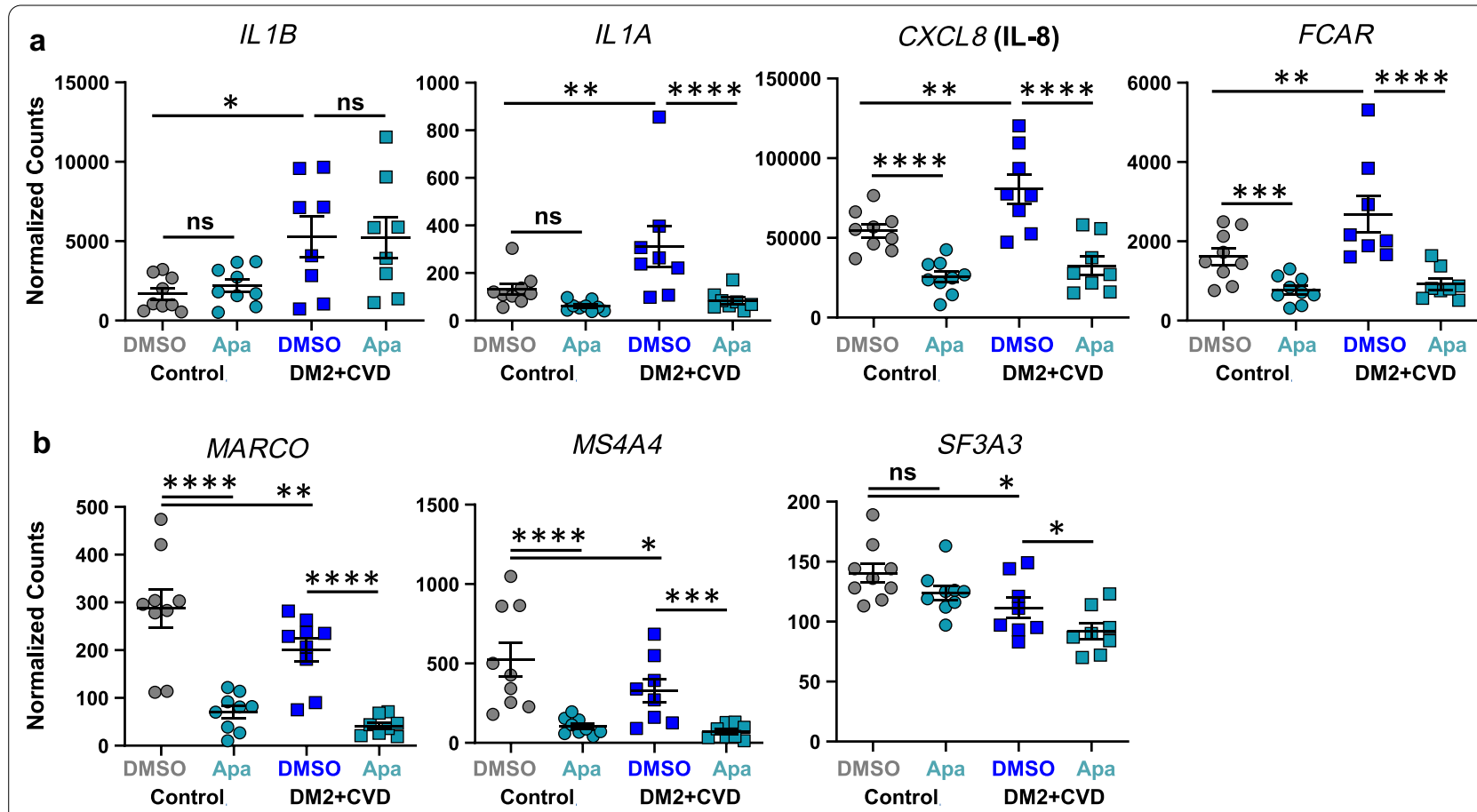

Fig. 2 Monocytes from DM2 + CVD patients and control subjects exhibit differential gene expression that is inhibited by $25 \mu \mathrm{M}$ apabetalone (Apa). a Pro-inflammatory genes that show elevated expression in DM2+CVD monocytes as compared to controls. b. Genes that show reduced expression in DM2 + CVD monocytes as compared to controls. Gene expression is expressed as endogenous control-normalized counts $\left(\right.$ NanoString $^{\mathrm{TM}}$ ). Statistics: 2-Way repeated measures ANOVA followed by Tukey's multiple comparisons correction for within-group comparisons, or Bonferroni's test for between-group comparisons; ${ }^{*} p<0.05 ;{ }^{* *} p<0.01$; ${ }^{* * *} p<0.001 ;{ }^{* * *} p<0.0001$; ns, non-significant. Individual patient data are shown as a mean \pm SEM 
Table 2 Apabetalone suppresses the expression of inflammatory genes in unstimulated monocytes obtained from DM2 + CVD patients and control subjects

\begin{tabular}{|c|c|c|c|c|}
\hline \multirow{2}{*}{ Function } & \multirow{2}{*}{ Gene name } & \multirow{2}{*}{$\begin{array}{l}\text { Gene } \\
\text { symbol }\end{array}$} & \multicolumn{2}{|c|}{$\begin{array}{c}\text { Mean fold expression } \\
25 \mu \mathrm{M} \text { apabetalone }\end{array}$} \\
\hline & & & DM2+CVD & Controls \\
\hline \multirow{8}{*}{$\begin{array}{l}\text { Cytokines and } \\
\text { chemokines }\end{array}$} & Monocyte chemoattractant protein-1 & CCL2 & 0.01 & 0.02 \\
\hline & Monocyte chemoattractant protein-3 & $\mathrm{CCL} 7^{\mathrm{b}}$ & 0.06 & 0.07 \\
\hline & $\mathrm{GRO} \alpha$ & $\mathrm{CXCL} 1^{\mathrm{b}}$ & 0.08 & 0.13 \\
\hline & ENA-78 & CXCL5 & 0.12 & 0.17 \\
\hline & GRO $\gamma$ & CXCL3 & 0.24 & 0.31 \\
\hline & Interleukin $1 \alpha$ & IL1A & 0.33 & 0.51 \\
\hline & Interleukin 8 & IL8 & 0.39 & 0.46 \\
\hline & GRO $\beta$ & CXCL2 & 0.40 & 0.46 \\
\hline \multirow{3}{*}{$\begin{array}{l}\text { Cytokine and chemokine } \\
\text { receptors }\end{array}$} & CD191 & $\mathrm{CCR} 1^{\mathrm{b}}$ & 0.13 & 0.15 \\
\hline & Interleukin 1 receptor, type I & IL1R1 & 0.28 & 0.33 \\
\hline & Interleukin 3 receptor, $\alpha$ & IL3RA & 0.43 & 0.42 \\
\hline \multirow{9}{*}{$\begin{array}{l}\text { Pattern recognition } \\
\text { receptors and signaling }\end{array}$} & Bgp-95 & CD180 & 0.07 & 0.06 \\
\hline & Cluster of differentiation 14 & CD14 ${ }^{b}$ & 0.15 & 0.20 \\
\hline & Cluster of differentiation 163 & CD163 $3^{b}$ & 0.41 & 0.40 \\
\hline & Formyl peptide receptor 1 & FPR1 $1^{b}$ & 0.38 & 0.50 \\
\hline & Toll-like receptor 1 & TLR1 & 0.39 & 0.47 \\
\hline & Formyl peptide receptor 2 & FPR2 & 0.42 & 0.51 \\
\hline & MD2 & LY96 & 0.52 & 0.67 \\
\hline & Toll like receptor 4 & TLR4 & 0.64 & 0.81 \\
\hline & Toll like receptor 6 & TLR6 & 0.69 & 0.81 \\
\hline \multirow{5}{*}{ Inflammatory signaling } & Caspase 1 & CASP $1^{\mathrm{b}}$ & 0.40 & 0.43 \\
\hline & Nuclear factor NF-кB p105 subunit & $\mathrm{NFKB} 1^{\mathrm{c}}$ & 0.61 & 0.79 \\
\hline & Myeloid differentiation primary response 88 & MYD88 & 0.66 & 0.77 \\
\hline & Interleukin-1 receptor-associated kinase 1 & IRAK $1^{\mathrm{c}}$ & 0.68 & 0.92 \\
\hline & Activator protein-1 subunit & FOS & 1.69 & 2.29 \\
\hline \multirow{4}{*}{ Immunoglobulin receptors } & Fc fragment of IgG, low affinity IIIb, receptor & FCGR3B & 0.28 & 0.33 \\
\hline & Fc fragment of IgA receptor & FCAR $^{b}$ & 0.35 & 0.48 \\
\hline & Leukocyte Ig-like receptor subfamily B member 2 & LILRB2 & 0.53 & 0.60 \\
\hline & Sialic acid-binding Ig-like lectin 5 & SIGLEC5 & 0.55 & 0.60 \\
\hline Scavenger receptors & Macrophage receptor with collagenous structure & MARCO & 0.25 & 0.27 \\
\hline \multirow{2}{*}{ Leukocyte infiltration } & Sialophorin & SPN & 1.72 & 2.09 \\
\hline & CD11c & ITGAX & 1.85 & 2.19 \\
\hline \multirow{2}{*}{ Complement cascade } & Complement component 3a receptor 1 & C3AR1 & 0.24 & 0.24 \\
\hline & Complement component 3 & $\mathrm{C} 3$ & 0.50 & 0.68 \\
\hline Thrombosis & Thrombospondin 1 & THBS $1^{b}$ & 0.09 & 0.08 \\
\hline ROS production & NADPH oxidase 2 & CYBB & 0.58 & 0.70 \\
\hline mRNA stability & Enhancer of mRNA-decapping protein 3 & $\mathrm{EDC}^{\mathrm{b}}$ & 0.38 & 0.41 \\
\hline Microtubule organization & Nucleotide binding protein 1 & NUBP1 & 0.65 & 0.81 \\
\hline Unknown function & Membrane spanning 4-domains A4A & MS4A4A & 0.24 & 0.23 \\
\hline
\end{tabular}

${ }^{a}$ Gene expression is expressed as mean fold difference in response to $25 \mu \mathrm{M}$ apabetalone treatment relative to vehicle (DMSO). ${ }^{\mathrm{b}} \mathrm{Genes}$ significantly downregulated in response to $5 \mu \mathrm{M}$ apabetalone. 'Genes differentially sensitive to apabetalone treatment in DM2 + CVD versus control cells (also shown in Fig. 3a). Italics numbers indicate a fold change of $>30 \%$ with an adjusted $p$ value $<0.05$ (two-way repeated measures ANOVA) 


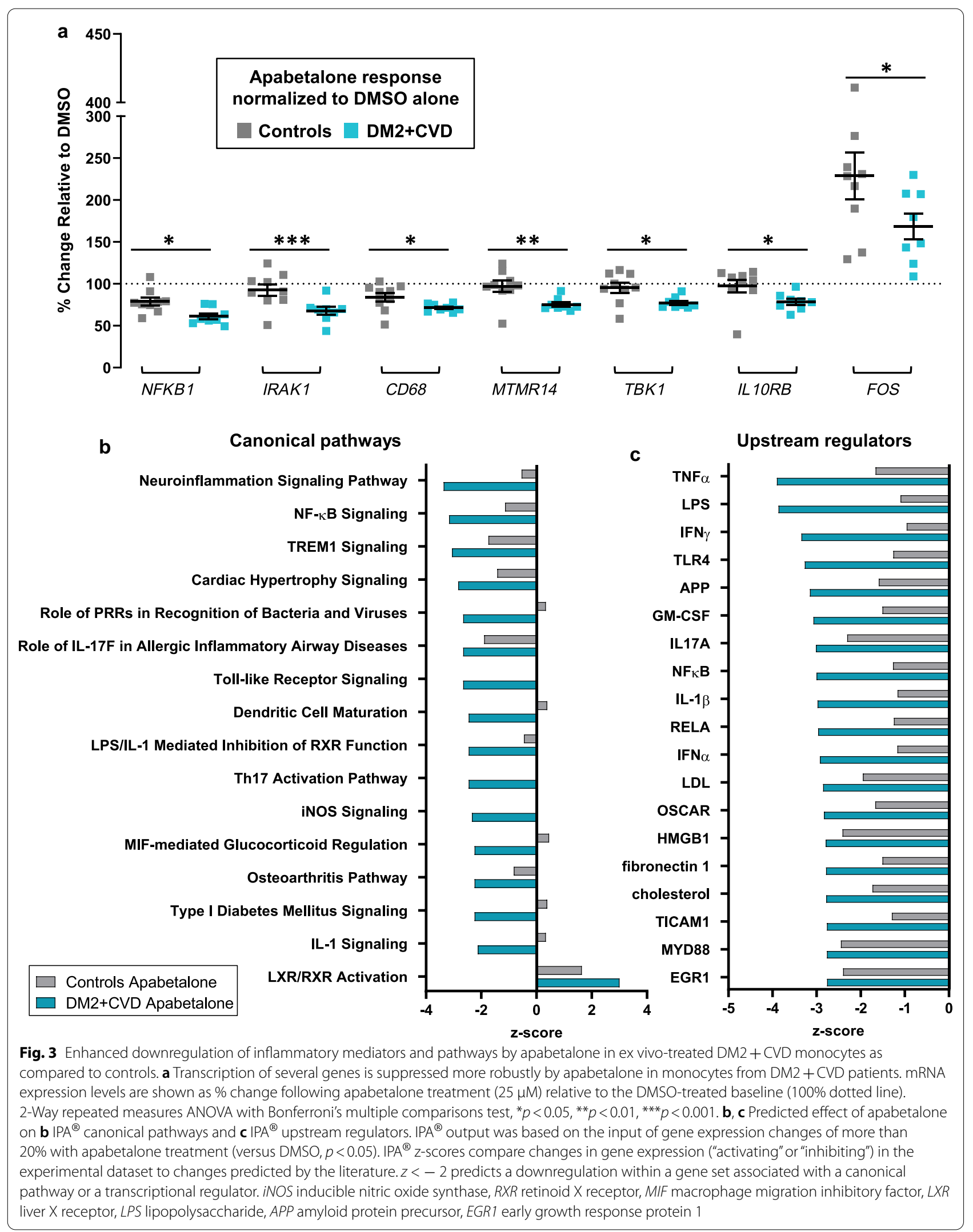


[43]. FOS, a transcription factor involved in myeloid differentiation [44], was induced by apabetalone treatment to a lesser extent in DM2 + CVD cells compared to control monocytes (Fig. 3a).

Apabetalone target genes ( $>20 \%$ change, $p<0.05$ following a $4 \mathrm{~h}$ treatment) were further examined with Ingenuity ${ }^{\circledR}$ pathway analysis $\left(\mathrm{IPA}^{\circledR}\right)$ software to predict affected canonical pathways and upstream regulators (Fig. 3b, c). Apabetalone was predicted to downregulate key canonical pathways associated with monocyte inflammatory responses, such as the NF- $\mathrm{kB}$ signalling, the TLR signalling, the IL-1 signalling and the NLRP3 inflammasome pathway (Fig. 3b and Additional file 4). IPA $^{\circledR}$ upstream regulator analysis predicted that apabetalone would suppress multiple transcriptional targets associated with cytokine signalling (TNF $\alpha$, IFN, IL-17, IL-1, GM-CSF) and TLR signalling (LPS, TLR4, NF- $\mathrm{kB}$, RELA, HMGB1, TICAM2, MYD88) (Fig. 3c and Additional file 5). Apabetalone had a greater inhibitory impact on these pathways and regulators in DM2 + CVD monocytes than in controls (as indicated by $z$-scores $<-2$ predicting a significant suppression of Upstream Regulator targets) (Fig. 3b, c). The data suggest that monocytes from diseased patients are activated via BET proteindependent pathways and that these monocytes are more sensitive to BET inhibition by apabetalone than those of matched subjects without CVD or DM2.

\section{Apabetalone counters DM2 + CVD monocyte hyper-responsiveness to IFNY}

IFNy is a pro-inflammatory cytokine produced by immune cells in the atherosclerotic plaque that initiates monocyte polarization into pro-inflammatory and tissue-destroying M1 macrophages [37]. BETi have previously been shown to regulate IFN $\alpha$ signalling in monocytes through inhibition of BRD4 association with gene expression regulatory elements [45]. To determine if apabetalone could impact BRD4 chromatin binding in response to IFN $\gamma$, we probed BRD4 occupancy of two IFN $\gamma$-sensitive genes, CXCL10 and ICAM1, in THP-1 monocytes [46, 47]. As expected, cytokine stimulation $(4 \mathrm{~h})$ induced a significant enrichment of BRD4 on the CXCL10 promoter ( $-44 \mathrm{bp}, 2.8$-fold) and enhancer ( $-5259 \mathrm{bp}, 13$-fold), but not in a BRD4-lacking control region (Fig. 4a). A similar induction was observed for the ICAM1 gene promoter $(-159 \mathrm{bp}, 3.2$-fold). This BRD4 enrichment was countered by co-treatment with apabetalone $(56 \%, 87 \%$ and $77 \%$ reduction, respectively), indicating that it was BD-dependent. Inhibition of BRD4 chromatin occupancy by apabetalone was consistent with the decrease in CXCL1O gene transcript levels measured after treatment (Fig. 4b). The ICAM1 mRNA transcript was not detectable $4 \mathrm{~h}$ post-induction (not shown).

To compare cell responses to IFN $\gamma$, DM2 + CVD and control monocytes were treated ex vivo with IFN $\gamma$ for $4 \mathrm{~h}$, followed by gene expression and protein secretion analysis. Significantly, IFNY evoked a greater induction of pro-inflammatory genes CCL8, TNF and RELA, relative to baseline, in DM2 + CVD monocytes as compared to control monocytes (blue squares versus grey circles) (Fig. 5a, between-group statistical significance is indicated by black vertical bars and asterisks). MYD 88 and $C C L 7$ transcripts were increased by IFNY only in DM2 + CVD monocytes; no significant change was detected in control monocytes, indicating differential sensitivity to the cytokine treatment between cohorts
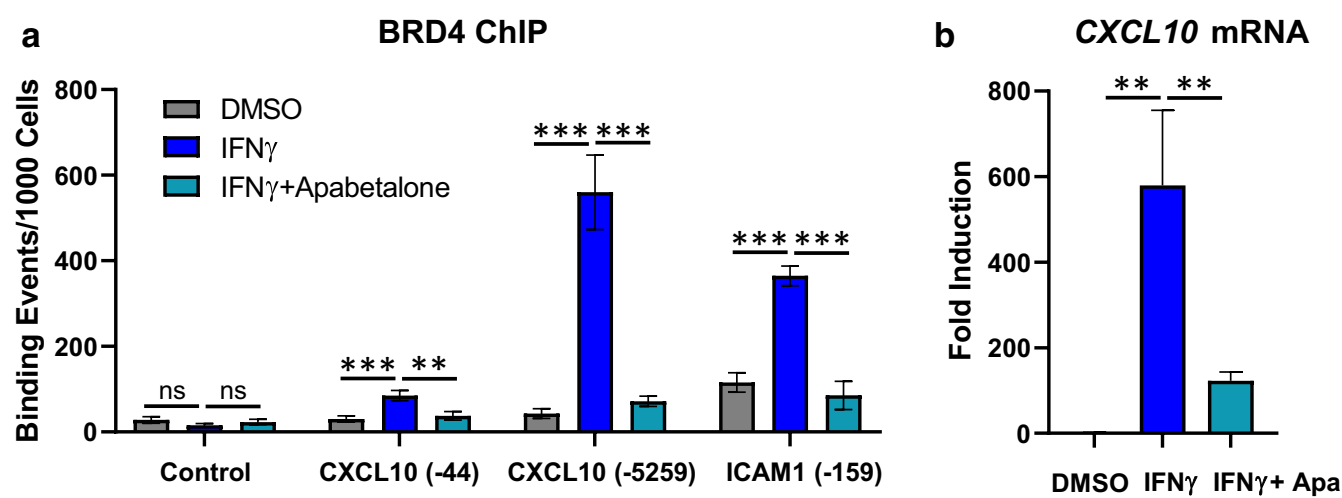

Fig. 4 Apabetalone treatment decreased BRD4 occupancy at transcription regulatory elements of IFNy-responsive genes. IFNy stimulation (4 h) increases BRD4 occupancy on the CXCL10 and ICAM1 gene regulatory regions, but not in a BRD4 protein-lacking region (Control) as determined by chromatin immunoprecipitation (ChIP). Co-treatment with apabetalone $(25 \mu \mathrm{M})$ reduces BRD4 association with gene regulatory regions. $\mathbf{b}$ Apabetalone $(25 \mu \mathrm{M})$ also suppressed CXCL10 mRNA transcript induction by IFNy in these same samples. Samples were processed in triplicate. Data are presented as the mean \pm S.D. Statistical significance was determined through ANOVA followed by Tukey's Multiple Comparison Test, where ${ }^{* *} p<0.01,{ }^{* * *} p<0.001$ and ns, no significant difference 

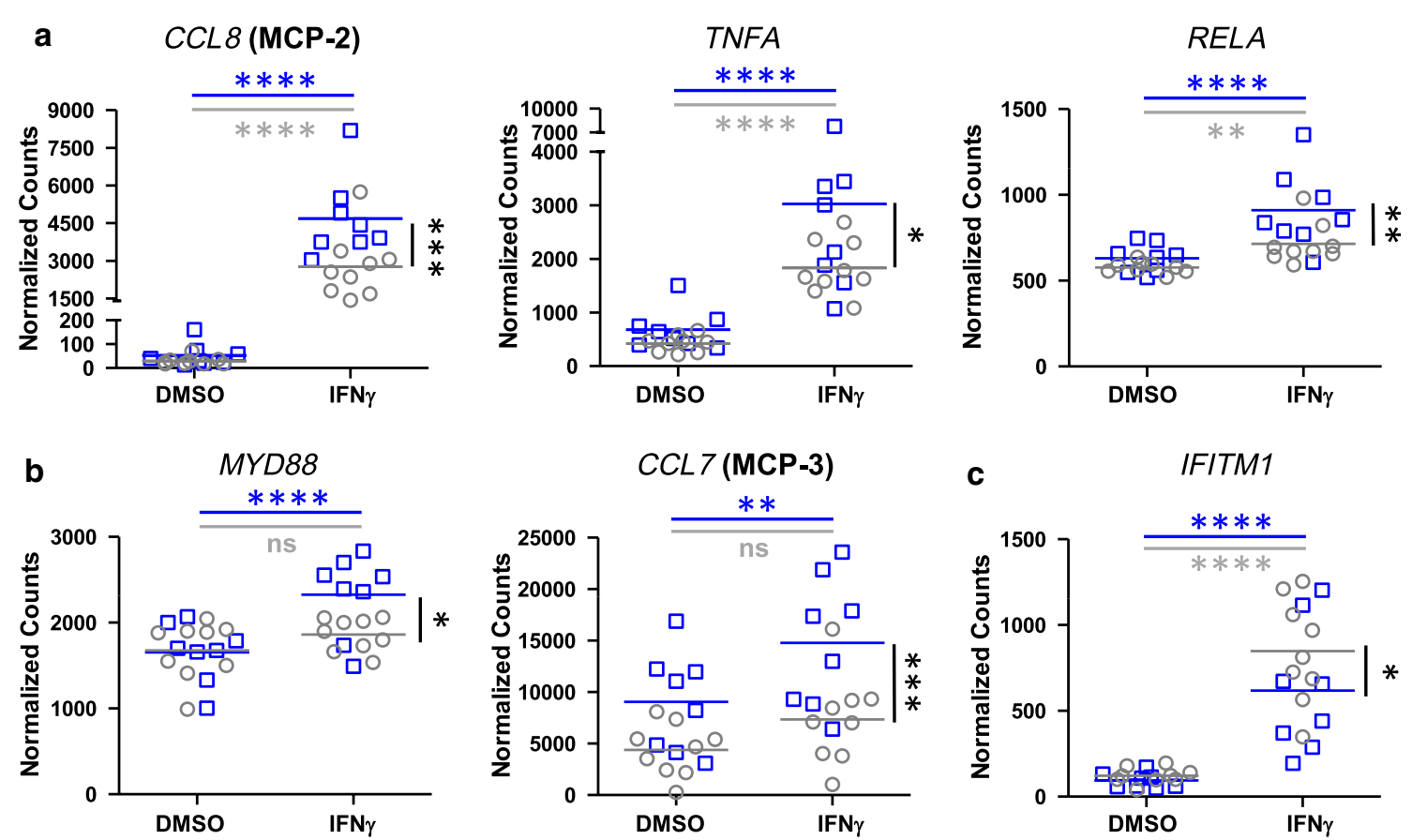

d $\quad \operatorname{CCL} 8(\mathrm{MCP}-2)$

TNFA
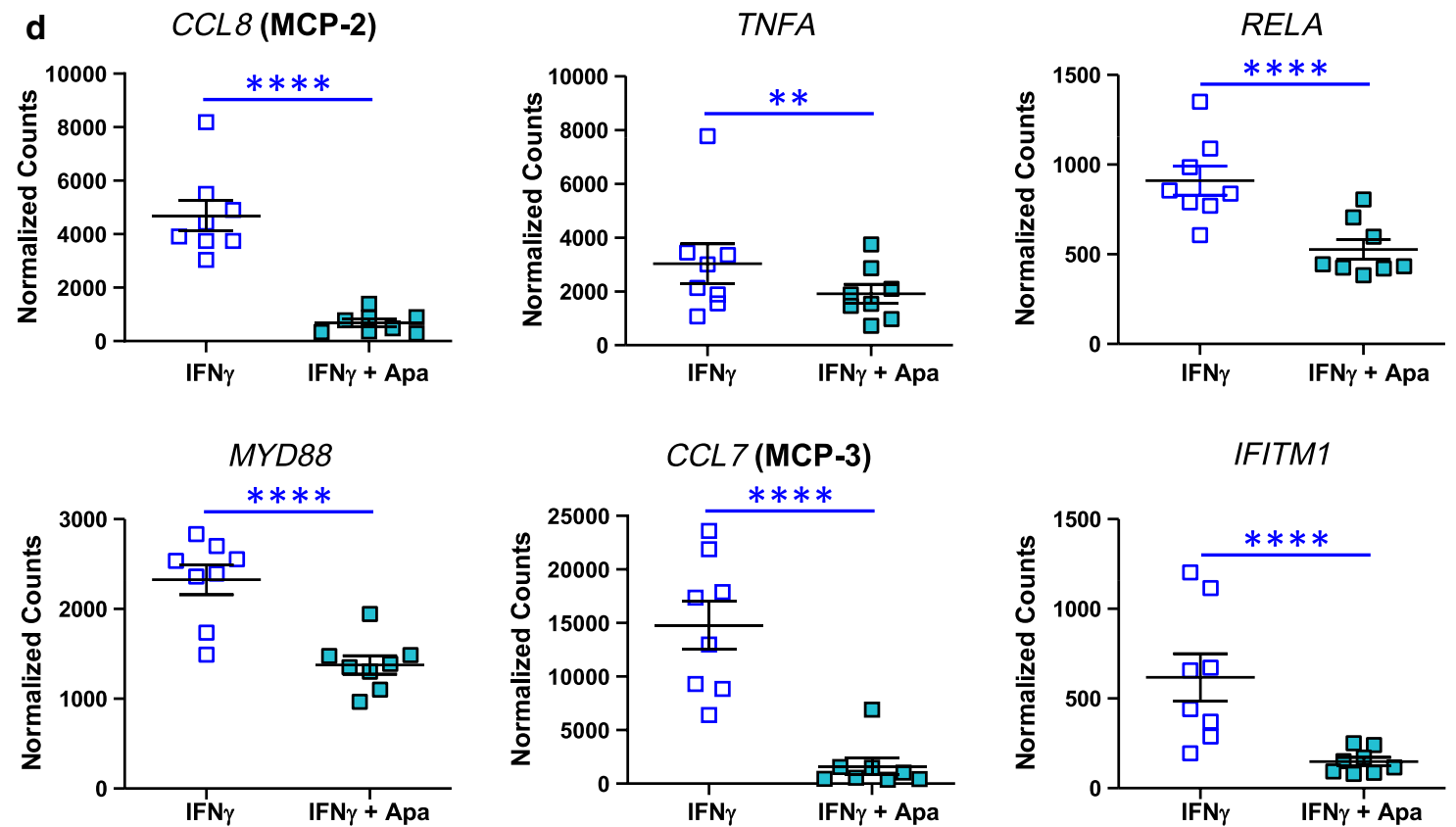

Fig. 5 Genes hyper-sensitive to IFNy stimulation are inhibited by $25 \mu \mathrm{M}$ apabetalone (Apa) in DM2 + CVD monocytes. a Hyper-activation of the transcriptional response to IFNy in monocytes obtained from DM2 + CVD patients (blue squares) compared to control cohort (grey circles). Gene expression changes are presented as means of endogenous control-normalized counts (Nanostring). b MYD88 and CCL7 are IFNY inducible in DM2 + CVD monocytes only. c IFITM2 is hyper-responsive in control monocytes. $\mathbf{d}$ Genes differentially responsive to IFNy are suppressed by apabetalone. Endogenous control-normalized counts are shown (NanoString). Statistics: 2-Way repeated measures ANOVA followed by Tukey's multiple comparisons test (within-group comparisons; blue bars and asterisks) or Bonferroni's test (between-group comparison; black bars and asterisks); ${ }^{*} p<0.05 ;{ }^{* *} p<0.01 ;{ }^{* * *} p<0.001 ;{ }^{* * *} p<0.0001$; ns non-significant. Individual patient data were shown as a mean \pm SEM 
(Fig. 5b) (blue versus grey horizontal bars and asterisks). IFITM1 transcripts increased in both monocyte populations with IFN $\gamma$ stimulation, but were enhanced more in control monocytes (Fig. 5c). Overall, these data indicate that DM2 +CVD monocytes are hyperactivated by the pro-M1 stimulant IFN $\gamma$, leading to an enhanced expression of chemokines and genes within the NF- $\mathrm{kB}$ pathway.

Previous reports have indicated that IFN $\gamma$ signalling is sensitive to BET inhibition $[25,45,48,49]$. Ex vivo treatment with apabetalone suppressed the transcription of genes that responded differentially to IFN $\gamma$, namely $C C L 8$, TNF, RELA, MYD88, CCL7 and IFITM1 (Fig. 5d and italics gene symbols in Table 3). The drug also countered IFN $\gamma$-stimulated secretion of the TNF $\alpha$ protein, consistent with gene expression data in DM2 + CVD monocytes (Fig. 6a). Secretion of IL-1 $\beta$, as measured by Milliplex ${ }^{\circledR}$ and ELISA assays, also declined with apabetalone treatment (Fig. 6b, c, respectively), even though the $I L 1 B$ transcription was not induced by IFN $\gamma$ nor suppressed by apabetalone (data not shown). This may be due to apabetalone-mediated downregulation of the CASP1 gene which is required for secretion of mature IL-1 $\beta$ (Tables 2 , 3; see Discussion) [50]. While apabetalone reduced the transcription of numerous genes induced by IFNY in both cohorts (Table 3), several IFNy-induced genes were differentially suppressed in DM2 + CVD monocytes as compared to controls (Fig. 7a). In most cases, apabetalone suppressed inflammatory gene transcription more efficiently in DM2 + CVD monocytes (MX1, IFIH1, TICAM2, MYD88, RELA). Transcripts of several genes (DDX58, TNFA, TLR4, RIPK2 and CASP1) were significantly decreased by BETi treatment only in DM2 + CVD monocytes (Fig. 7a, Table 3). Uniquely, induction of IFNY target gene STAT1 was differentially enhanced by apabetalone (Fig. 7a, Table 3). Overall, these data suggest that the transcriptional response induced by IFN $\gamma$ has a greater BET-dependency and is more sensitive to apabetalone in DM2 + CVD monocytes than in control cells.

Functionally, the gene transcripts responsive to IFNY and regulated by apabetalone can be categorized as cytokines, pattern recognition receptors, inflammatory signalling and anti-microbial response molecules (Table 3). Based on gene expression changes following IFN $\gamma$ treatment of control and DM $2+$ CVD monocytes $(>20 \%, p<0.05), \mathrm{IPA}^{\circledR}$ predicted a significant upregulation of a canonical pathway linked to pattern recognition receptor (PRR) signalling $(p<0.0001, z$-score $>2)$ (Fig. 7b and Additional file 6). Apabetalone treatment was predicted to significantly reverse the activation of the PRR signalling pathway only in DM2 + CVD monocytes $(z$-score $<-2)$ as no significant directional effect of apabetalone was predicted in control monocytes $(2>z$-score $>-2)$ (Fig. 7b). The IPA ${ }^{\circledR}$ upstream regulator analysis showed that IFN $\gamma$ target genes play a role downstream of key cytokines and transcription factors involved in macrophage differentiation and activation (Fig. 7c and Additional file 7). While apabetalone also had a significant inhibitory effect on the IFN $\gamma$ dependent inflammatory pathways in control monocytes (Fig. 7c; grey hatched bars), the predicted suppression of gene signatures was more pronounced in DM2 + CVD monocytes (Fig. 7c; teal hatched bars). Taken together, IFN $\gamma$-mediated gene transcription was countered by BET inhibition more efficiently in DM2 + CVD monocytes as compared to controls. Overall, our findings suggest that the transcriptional responsiveness of IFN $\gamma$-regulated genes is more dependent on BET proteins in the diseased state.

\section{Discussion}

In this study, we compared the pro-inflammatory activity of monocytes derived from DM2 + CVD patients on standard of care therapy versus matched control subjects. Monocytes from DM2 + CVD patients exhibited a hyper-inflammatory state characterized by increased gene expression of pro-inflammatory cytokines IL-8, IL- $1 \alpha$ and IL- $1 \beta$ and of the IgA receptor FCAR (also known as CD89). At the protein level, we observed enhanced surface expression of TLR2 in intermediate $\left(\mathrm{CD} 14^{++} \mathrm{CD} 16^{+}\right)$and non-classical $\left(\mathrm{CD} 14^{+} \mathrm{CD} 16^{+}\right)$ DM2 + CVD monocytes and increased secretion of chemoattractants IL-8 and GRO $\alpha$ (CXCL1) (Fig. 1). These changes in gene and protein abundance suggest that the monocytes circulating in DM2 + CVD patients adopt a pro-inflammatory phenotype despite standard of care therapy including statins.

Enhanced TLR2 expression had previously been reported on monocytes from DM2 and metabolic syndrome patients [38-40]. TLR2 is a pattern recognition receptor that recognizes molecular danger signals that are linked to microbial infection or sterile tissue injury. It is also crucial in the initiation and progression of atherosclerosis, since it stimulates foam cell formation [51]. Statins are reported to decrease monocyte TLR expression in DM patients [52-54]. However, statin therapy did not normalize monocyte TLR2 expression in our DM2 + CVD cohort. TLR2 activation induces the expression of cytokines, chemokines and cell adhesion molecules by immune cells, promoting na pro-inflammatory phenotype [55]. Similarly, FCAR activation by immunoglobulin A enhances production of pro-inflammatory cytokines, prostaglandins and leukotrienes [56-58]. Enhanced TLR and/or FCAR surface expression may underlie the observed hyperactive transcription of $I L 1 A$, $I L 1 B$ and $C X C L 8$ as well as enhanced secretion of IL-8 and GRO $\alpha$ in DM2 + CVD monocytes observed in this 
Table 3 Ex vivo treatment with apabetalone counters IFNy-mediated induction of gene expression in monocytes

\begin{tabular}{|c|c|c|c|c|c|c|}
\hline \multirow{3}{*}{ Function } & \multirow{3}{*}{ Gene name } & \multirow{3}{*}{$\begin{array}{l}\text { Gene } \\
\text { symbol }\end{array}$} & \multicolumn{4}{|c|}{$\begin{array}{c}\text { Gene expression } \\
\text { (mean fold change) }\end{array}$} \\
\hline & & & \multicolumn{2}{|c|}{ DM2+CVD } & \multicolumn{2}{|c|}{ Controls } \\
\hline & & & IFNy $\boldsymbol{\gamma}^{a}$ & $\mathrm{Apa}^{\mathrm{b}}$ & IFN $\gamma^{a}$ & Apa $^{b}$ \\
\hline \multirow{10}{*}{ Cytokines } & Interferon gamma-induced protein 10 & CXCL10 & 755 & 0.39 & 1023 & 0.45 \\
\hline & Monokine induced by gamma interferon & CXCL9 & 297 & 0.20 & 364 & 0.11 \\
\hline & Monocyte chemoattractant protein 2 & $C C L 8^{C}$ & 135 & 0.15 & 116 & 0.17 \\
\hline & Tumor necrosis factor alpha & $T N F^{d}$ & 4.46 & 0.67 & 4.68 & 0.92 \\
\hline & Monocyte chemoattractant protein 1 & $\mathrm{CCL} 2^{\mathrm{c}}$ & 2.21 & 0.09 & 2.46 & 0.04 \\
\hline & Monocyte-chemotactic protein 3 & $C C L 7^{c}$ & 1.75 & 0.10 & 1.95 & 0.07 \\
\hline & Interleukin 3 receptor, alpha & IL3RA & 1.53 & 0.55 & 1.53 & 0.64 \\
\hline & GROB & CXCL2 & 0.57 & 0.26 & 0.55 & 0.26 \\
\hline & Interleukin 8 & IL8 & 0.42 & 0.33 & 0.37 & 0.31 \\
\hline & GRO $\alpha$ & CXCL1 & 0.38 & 0.12 & 0.51 & 0.16 \\
\hline Cytokine receptor & C-C chem okine receptor type 1 & CCR1' & 1.40 & 0.21 & 1.34 & 0.19 \\
\hline \multirow{7}{*}{$\begin{array}{l}\text { Pattern recognition } \\
\text { receptors }\end{array}$} & Toll like receptor 8 & TLR8 & 6.77 & 0.32 & 5.14 & 0.33 \\
\hline & TIR domain-containing adapter molecule & TICAM $^{\mathrm{d}}$ & 2.67 & 0.56 & 2.67 & 0.73 \\
\hline & Myeloid Differentiation factor 2 & LY96 & 2.12 & 0.33 & 2.38 & 0.39 \\
\hline & Formyl Peptide Receptor 2 & FPR2 & 1.67 & 0.42 & 1.55 & 0.54 \\
\hline & Toll like receptor 1 & TLR1 & 1.50 & 0.40 & 1.28 & 0.53 \\
\hline & Toll like receptor 4 & TLR4 $^{d}$ & 1.53 & 0.69 & 1.59 & 0.95 \\
\hline & Bgp-95 & CD180 & 0.39 & 0.18 & 0.41 & 0.15 \\
\hline LDL receptor & Macrophage scavenger receptor 1 & MSR1 $^{c}$ & 3.36 & 0.21 & 3.49 & 0.22 \\
\hline \multirow{7}{*}{ Inflammatory signaling } & Signal transducer and activator of transcription 1 & STAT1 ${ }^{c d}$ & 16.8 & 1.95 & 20.6 & 2.74 \\
\hline & Receptor-interacting ser/thr-protein kinase 2 & RIPK2 $^{\mathrm{d}}$ & 3.85 & 0.74 & 4.04 & 1.00 \\
\hline & Caspase 1 & CASP1 ${ }^{d}$ & 1.50 & 0.77 & 1.43 & 1.05 \\
\hline & Nuclear factor NF-kappa-B p65 subunit & $\operatorname{Re} / A^{\mathrm{d}}$ & 1.43 & 0.58 & 1.24 & 0.82 \\
\hline & Myeloid differentiation primary response 88 & $M Y D 88^{d}$ & 1.41 & 0.60 & 1.14 & 0.78 \\
\hline & Interleukin-1 receptor-associated kinase 2 & IRAK2 & 0.68 & 0.64 & 0.64 & 0.88 \\
\hline & Interleukin-1 receptor-associated kinase 1 & IRAK1 & 0.66 & 0.65 & 0.64 & 0.88 \\
\hline \multirow{5}{*}{ Anti-microbial response } & Retinoic acid-inducible gene I & DDX58 ${ }^{d}$ & 11.2 & 0.56 & 10.1 & 0.78 \\
\hline & Interferon-induced GTP-binding protein & $M \times 1^{\text {cd }}$ & 10.0 & 0.34 & 9.42 & 0.42 \\
\hline & 2'-5'-oligoadenylate synthetase & OAS3 & 8.61 & 0.32 & 10.6 & 0.33 \\
\hline & Interferon-induced transmembrane protein 1 & IFITM1 ${ }^{c}$ & 7.11 & 0.28 & 9.30 & 0.34 \\
\hline & Interferon induced with helicase $\mathrm{C}$ domain 1 & $\mathrm{IFIH} 1^{\mathrm{d}}$ & 6.03 & 0.50 & 6.12 & 0.66 \\
\hline Immunom odulation & Indoleamine-pyrrole 2,3-dioxygenase & IDO1 $^{c}$ & 341 & 0.08 & 378 & 0.05 \\
\hline ROS production & NADPH oxidase 2 & CYBB & 1.66 & 0.60 & 1.66 & 0.70 \\
\hline $\begin{array}{l}\text { mRNA stability, nuclear } \\
\text { export, and translation }\end{array}$ & Zinc finger $\mathrm{CCCH}$-type containing 14 & ZC3H14 & 0.65 & 1.46 & 0.60 & 2.09 \\
\hline $\begin{array}{l}\text { Immunoglobulin } \\
\text { receptor }\end{array}$ & Fc fragment of IgA receptor & FCAR & 0.58 & 0.35 & 0.49 & 0.40 \\
\hline Thrombosis & Thrombospondin 1 & THBS1 & 0.54 & 0.08 & 0.47 & 0.05 \\
\hline
\end{tabular}


Table 3 (continued)

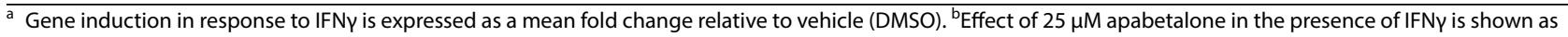
a mean fold change in gene expression relative to IFN $\gamma$ stimulation alone. ${ }^{\mathrm{C}} \mathrm{Genes}$ significantly downregulated in response to $5 \mu \mathrm{M}$ apabetalone. Italics gene symbols indicate an enhanced response to IFNy in DM2 + CVD monocytes (as compared to controls, also Fig. 5). ${ }^{\mathrm{d}}$ Genes differentially sensitive to apabetalone treatment in DM2 + CVD versus control cells (also Fig. 7a). Italics numbers indicate fold change with an adjusted $p$ value $<0.05$ ( 2 -way repeated measures ANOVA)
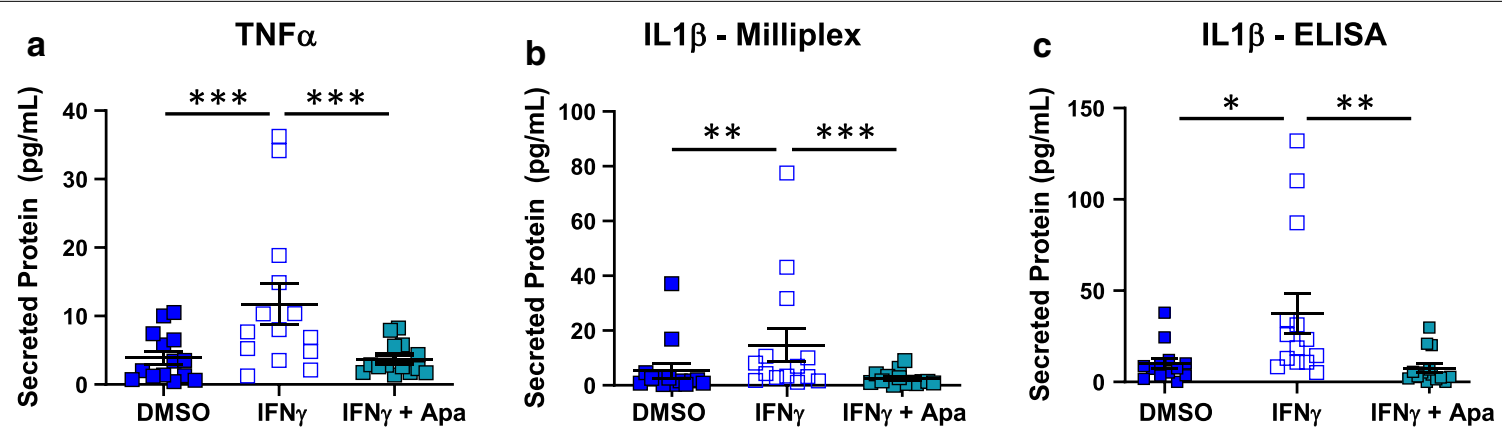

Fig. 6 Apabetalone counters stimulated cytokine secretion in DM2 +CVD monocytes. $\mathbf{a}$, b Secretion of proteins induced by IFNy in DM2 + CVD monocytes is countered by $25 \mu \mathrm{M}$ apabetalone (Apa) $24 \mathrm{~h}$ post-treatment (Milliplex ${ }^{\circledR}$ ). c Secretion of IL-1 b in DM2 + CVD monocytes was confirmed by ELISA. Statistics: 2-Way repeated measures ANOVA followed by Tukey's multiple comparisons test; ${ }^{*} p<0.05 ;{ }^{* *} p<0.01 ;{ }^{* * *} p<0.001$. Individual patient data were shown as a mean \pm SEM

study. Elevated levels of these cytokines have previously been described in DM2 and CVD patients [59-61]. These pro-inflammatory mediators are highly pro-atherogenic as they promote differentiation to a M1-like macrophage phenotype, enhanced vascular wall recruitment and increased endothelial transmigration [62-66]. Thus, their overproduction likely contributes to the pathogenesis of atherosclerosis in DM2 + CVD patients on standard of care therapy.

A number of genes were downregulated in monocytes isolated from DM2 + CVD patients (relative to controls), including the mRNA splicing complex encoding gene $S F 3 A 3$, the scavenger receptor $M A R C O$ and the plasma membrane tetraspan gene MS4A4. The latter two genes are expressed on monocytes with anti-inflammatory M2-like characteristics [67, 68], whereas the SF3A3 gene negatively regulates pro-inflammatory TLR signalling [69]. Thus, downregulation of these genes may indicate reprogramming towards a pro-inflammatory phenotype in patients. Upon IFN $\gamma$ stimulation, monocytes acquire a M1-like phenotype characterized by enhanced cytokine production, phagocytosis and intracellular killing of microbial pathogens [70]. We show that monocytes isolated from DM2 + CVD patients are more responsive to IFNy ex vivo treatment, with enhanced expression of genes that encode the NF- $\mathrm{kB}$ inflammatory pathway components (TNF, MYD88 and RELA) and chemokines (CCL7 and CCL8). Our observations are consistent with previous studies reporting that monocytes from CVD patients (53\% of whom also had DM2) overproduce cytokines in response to treatment with IFNy combined with lipopolysaccharide [8]. Overall, the observed gene expression and secretory profile of DM2 + CVD monocytes indicate a potential phenotypic shift from the M2-like state towards the pro-inflammatory M1-like state.

This persistent hyper-responsive phenotype is likely linked to changes to the epigenetic landscape characteristic of cardiometabolic disease [14, 19]. In human monocytes exposed to hyperglycemic conditions ex vivo, there is a decrease in transcription inhibiting histone methylation marks and an increase in open chromatin marks, potentially enhancing transcription factor accessibility to DNA $[17,71,72]$. Congruently, in monocytes from diabetic patients, transcription-activating acetylation marks are more abundant on the promoters of pro-inflammatory genes encoding TNF $\alpha$ and cyclooxygenase-2 (PTGS) [71, 72]. Transcription-activating acetylation of histone 3 lysine 27 (H3K27) and methylation of H3K4 is also increased in immune and vascular smooth muscle cells isolated from atherosclerotic plaques in human carotids [73]. BET proteins "read" histone acetylation patterns including H3K27, thereby activating aberrant gene expression in diseased or stimulus-activated cells [23, $28,30]$. However, it is unclear if excessive BET activity contributes to pro-inflammatory monocyte response in DM2 + CVD patients.

Here, we demonstrate that the BET inhibitor apabetalone disrupts pro-inflammatory gene expression in hyperactive DM2 + CVD monocytes. Indeed, in unstimulated 


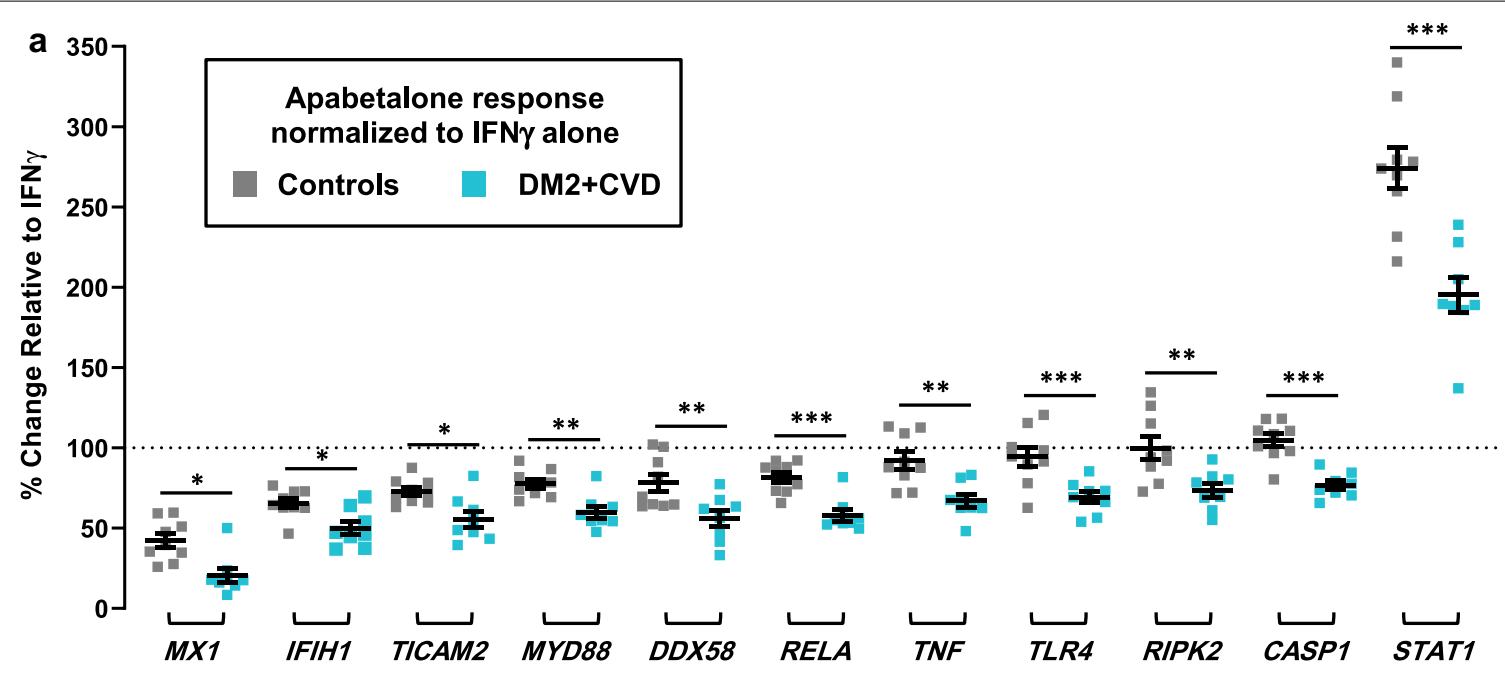

b

C Upstream regulators

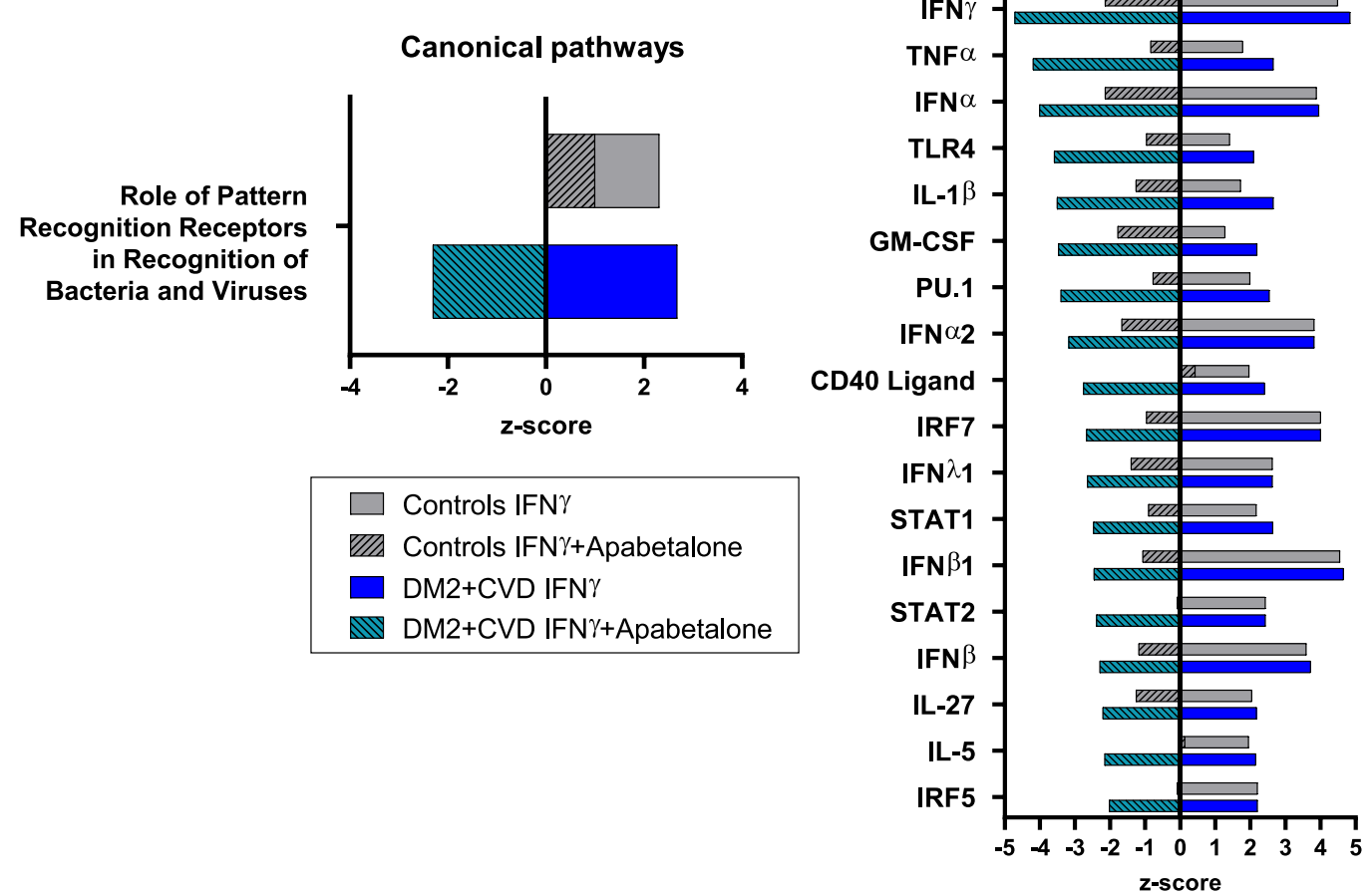

Fig. 7 Differential effects of apabetalone treatment on IFNY-sensitive inflammatory mediators and pathways in DM2 + CVD monocytes as compared to controls. a Apabetalone suppresses select IFNY-induced genes more robustly in monocytes from DM2 + CVD patients as compared to controls. Apabetalone's effect on gene expression in the presence of IFN $y$ was calculated relative to IFNy only condition (100\% dotted line). Statistical significance was determined using 2-way repeated measures ANOVA with Bonferroni's multiple comparisons test, ${ }^{*} p<0.05$, ${ }^{* *} p<0.01$, ${ }^{* * *} p<0.001$. b, c Predicted effect of IFN $\gamma$ and IFN $y+$ apabetalone treatment on IPA ${ }^{\circledR}$-curated canonical pathways and upstream regulators. IPA ${ }^{\circledR}$ output was based on the input of gene expression changes of more than $20 \%$ with apabetalone treatment (versus DMSO, $p<0.05$ ). IPA ${ }^{\circledR} z$-scores compare changes in gene expression ("activating" or "inhibiting") in the experimental dataset to changes predicted by the literature. $z<-2$ predicts a downregulation and $z>2$ predicts an upregulation within a gene set associated with a canonical pathway or a transcriptional regulator. $n / d$ no predicted directional change, IRF interferon response factor; PRRs pattern recognition receptors, R/G-I retinoic acid-inducible gene I 
conditions, apabetalone suppresses numerous genes more efficiently in DM2 + CVD monocytes, including those associated with cytokine, TLR and NF- $\mathrm{KB}$ signalling. Of note, even in baseline conditions, apabetalone significantly reduces the IFN $\gamma$ transcriptional signature in DM2 + CVD monocytes (but not in control cells), suggesting that IFN $\gamma$ target genes are hyperactive in diabetic monocytes. Our data agrees with previously published observations, showing that IFN $\gamma$ target genes can be induced by high glucose in ex vivo cultured human monocytes [17]. Further, upon ex vivo IFN $\gamma$ stimulation, the TLR pathway and the cytokine transcriptional networks were predicted to be downregulated by apabetalone, especially in DM2 + CVD monocytes (Fig. 7). This differential response to apabetalone treatment suggests that $\mathrm{BET}$ proteins drive the disease-associated IFN $\gamma$ signature in DM2 + CVD patients' monocytes. Interestingly, monocytes from systemic sclerosis patients also display BETi-sensitive IFN signatures, similarly to the DM2 + CVD monocytes studied here [74]. We have shown that apabetalone can dislodge BRD4 from chromatin during IFN $\gamma$-mediated induction of model genes CXCL10 and ICAM1 in an in vitro monocyte model, providing insight into the drug's mechanism of action. However, further epigenetic studies will be required to explain the differential sensitivity to BET inhibition between non-diseased and diseased cells.

Macrophages present in the atherosclerotic plaque are largely derived from circulating monocytes infiltrating blood vessels' walls $[7,75]$. In mice, monocytes have been shown to enter into the plaque more readily in the context of diabetes and hypercholesterolemia [76-78]. In non-stimulated conditions, apabetalone suppressed protein secretion of key monocyte chemoattractants MCP-1, MCP-3, GRO- $\alpha$ and IL-8 (87\%, 79\%, 55\% and $32 \%$ reduction in DM2 + CVD monocytes, respectively). Apabetalone treatment also potently downregulated the transcription of genes differentially induced by IFN $\gamma$ in DM2 + CVD monocytes, including the pro-inflammatory cytokine $T N F$ gene (33\% reduction), and monocyte chemokine genes CCL7 and CCL8 (90\% and $85 \%$ reduction, respectively). Additional chemokines that promote chemotaxis and tissue extravasation, CCL2 [62, 64], CXCL9 [79] and CXCL1O [79], were induced by IFNY in both monocyte populations and were strongly suppressed by apabetalone $(91 \%, 80 \%$ and $61 \%$ reduction, respectively) (Table 3 ). BETi treatment is thus predicted to reduce the migratory phenotype of DM2 +CVD monocytes, potentially preventing atherosclerotic plaque infiltration by activated monocytes.

Upon stimulation with cytokines and PRR agonists, monocytes and macrophages activate the inflammasome pathway, which is responsible for the production of the mature secreted form of IL-1 $\beta$, a major pro-atherosclerotic cytokine [50]. IFN $\gamma$ contributes to high $I L 1 B$ gene expression only when combined with secondary stimuli [80]. Consistent with published data [80], IFNY did not change the $I L 1 B$ transcript abundance as a single agent (data not shown), but it enhanced the IL-1 $\beta$ protein secretion by 2.7 -fold in DM2 + CVD monocytes (Fig. 6). This induction was countered by apabetalone treatment ( $84 \%$ reduction). IL-1 $\beta$ is synthesized by monocytes in its inactive form (pro-IL-1 $\beta$ ), which is then converted into its active mature form by the NLRP3 inflammasome-associated caspase 1 protease (encoded by CASP1 gene) [50]. Apabetalone $(25 \mu \mathrm{M})$ downregulated CASP1 gene transcription in DM2 + CVD monocytes in nonstimulated (Table 2) and stimulated (Table 3 ) conditions, potentially explaining the observed decrease in IL- $1 \beta$. The severity of atherosclerosis correlates with inflammasome activity and NLRP3/caspase 1-mediated generation of IL-1 $\beta$ and IL- $1 \alpha$ in human atherosclerotic plaque [81]. Interestingly, the anti-IL-1 $\beta$ monoclonal antibody canakinumab reduced the risk of MACE for CVD patients by $15 \%$ in 3.7 years, independently of lipid lowering [82]. This proof-of-concept study demonstrated that countering inflammasome-mediated inflammation significantly reduces residual CVD risk, promoting the development of new anti-inflammatory therapeutic agents.

\section{Conclusions}

We have demonstrated that monocytes isolated from DM2 + CVD patients exhibit a hyper-inflammatory phenotype at baseline and a hyper-responsiveness to inflammatory stimuli ex vivo. This activated monocyte state may contribute to the initiation and progression of atherosclerosis and increased cardiovascular risk in these patients. Ex vivo BET-inhibition by apabetalone reduces this enhanced pro-inflammatory phenotype, providing a rationale for further evaluation of BET inhibitors as therapeutic agents for high risk DM2+CVD patients. Previously, a post hoc analysis of pooled phase 2 trials of CVD patients indicated that apabetalone reduced MACE (5.9\% in the treatment group compared to $10.4 \%$ in the placebo group; $p=0.02$ ) [83]. In a subgroup analysis of patients with DM2, apabetalone further reduced the MACE hazard ratio to 0.38 (95\% CI $0.15-0.99 ; p=0.04$ ) [83]. In the recently completed phase 3 cardiovascular outcomes trial (BETonMACE), 2425 patients with DM2 and recent acute coronary syndrome were treated with apabetalone or placebo, and followed for 26 months [84, 85]. Although the primary endpoint of the study, a reduction in time to first occurrence of MACE defined as CV death, non-fatal myocardial infarction or stroke, did not achieve statistical significance, apabetalone did demonstrate benefits on hospitalization for heart failure [85]. As 
monocyte activation and infiltration contributes to heart failure, apabetalone treatment may counter the detrimental immune inflammatory response in patients with post-acute coronary syndrome and DM2.

\section{Materials and methods Study design}

This observational mono-centre cohort study enrolled subjects diagnosed with DM2 and high CVD risk (myocardial infarction, percutaneous coronary intervention, coronary artery bypass graft, peripheral arterial disease, episode of unstable angina, transient ischemic event, cerebrovascular accident or peripheral arterial disease, but event-free in past 3 months) and age and gender matched volunteers (Table 1). Exclusion criteria consisted of a history of chronic kidney disease stage 3b-5, malignant diseases or any clinically significant medical condition within the past 2 years that could interfere with the conduct of the study in the opinion of the investigator, treatment with immunosuppressants within the 3 months prior to visit 1 and evident drug or alcohol use. The study protocol was approved by the medical ethical committee of the Amsterdam Medical Centre in Amsterdam, the Netherlands. Each subject provided written informed consent.

\section{Biochemical measurements}

Blood was collected while patients were in a fasting state. Plasma total cholesterol, high-density lipoprotein (HDL) cholesterol, triglycerides and lipoprotein(a) levels were analysed using commercially available methods. Lowdensity lipoprotein cholesterol levels were calculated using the Friedewald equation.

\section{PBMC isolation and monocyte culture}

Peripheral blood mononuclear cells (PBMCs) were isolated from DM2 + CVD subjects and healthy controls by Ficoll density gradient centrifugations (Axis-Shield) as described in detail previously [86]. In brief, after washing PBMCs, CD14 ${ }^{+}$monocytes were isolated using human CD14 magnetic beads and MACS ${ }^{\circledR}$ cell separation columns according to manufacturer's instructions (Miltenyi Biotec, Leiden, The Netherlands). Then, these $\mathrm{CD}_{14}{ }^{+}$monocytes were ex vivo treated with IFN $\gamma$ and/ or apabetalone, and phenotyped for gene expression (NanoString) and protein secretion (Millipore Milliplex ${ }^{\circledR}$ Human Cytokine/Chemokine Array).

\section{Flow cytometry}

Whole blood was collected from DM2 + CVD patients and matched controls in EDTA tubes. After lysis of red blood cells with red blood cell lysis buffer $10 \times$ (eBioscience), white blood cells were stained with antibodies for cell surface markers CCR2, CD11c, CD36, CD29, CCR5, CD33, CD32, TLR2, CD11b,CCR7, CD163, TLR4, HLA-DR, CD14, CD16, IVIG. Fluorescence was measured using a FACS CANTO II (BD) and analysed with FlowJo software version V10.6. Monocyte area was gated based on forward and side scatter, $\mathrm{CD} 14^{+}$and/or $\mathrm{CD}_{16}{ }^{+}$and HLA-DR. Monocytes were classified as classical $\left(\mathrm{CD} 14^{++} \mathrm{CD} 16^{-}\right)$, intermediate $\left(\mathrm{CD} 14^{++} \mathrm{CD} 16^{+}\right)$or non-classical $\left(\mathrm{CD} 14^{+} \mathrm{CD} 16^{+}\right)$. The expression of cell surface markers was calculated as the delta geometric mean $(\Delta \mathrm{GM}) . \Delta \mathrm{GM}=\mathrm{GM}$ surface staining-GM unstained control. Statistical differences in cell surface marker abundance between DM2 + CVD patient monocytes and controls were determined using a Student's $t$-test.

\section{Multiplexed gene expression analysis via nanostring}

$\mathrm{CD}_{14}{ }^{+}$monocytes from 8 DM2 $+\mathrm{CVD}$ patients and 9 control subjects were pre-incubated with DMSO $(0.025 \%)$ or apabetalone ( 5 or $25 \mu \mathrm{M}$ ) for $1 \mathrm{~h}$, followed by IFNY $(25 \mathrm{U} / \mathrm{ml})$ co-stimulation for $4 \mathrm{~h}$. Non-stimulated samples received DMSO or apabetalone for $4 \mathrm{~h}$. Monocytes were lysed with TriPure (Roche, Basel, Switzerland), and total RNA was isolated and analysed using the nCounter ${ }^{\circledR}$ Vantage $3 \mathrm{D}^{\mathrm{TM}}$ Innate Immunity Panel (NanoString) (University of Alberta) for multiplexed single molecule counting of 180 human gene transcripts. Data were analysed using nSolver ${ }^{\mathrm{TM}}$ and Ingenuity ${ }^{\circledR}$ Pathway Analysis $\left(\right.$ IPA $\left.^{\circledR}\right)$. IPA ${ }^{\circledR} \mathrm{z}$-scores compare the observed differential regulation of a gene ("activating" or "inhibiting") in the dataset to changes predicted by the literature. $z<-2$ predicts a downregulation, and $z>2$ predicts an upregulation within a gene set associated with a canonical pathway or a transcriptional regulator. $p$ value $<0.01$ indicates a statistically significant overlap between the dataset genes and the curated gene sets (Fisher's exact test).

\section{Real-time PCR}

To assess BRD2, BRD3 and BRD4 expression, total RNA extracted from monocytes was reverse transcribed with High-Capacity cDNA RT Kit (Thermofisher Scientific) and amplified using TaqMan ${ }^{\text {TM }}$ Gene Expression Master Mix and TaqMan Real-Time PCR assays (Applied Biosystems). Gene expression was normalized to the endogenous control cyclophilin A (duplex reaction). Data were acquired using the ViiA-7 rtPCR System (Applied Biosystems).

\section{Multianalyte immunoprofiling}

In unstimulated conditions, monocytes were treated with DMSO $(0.025 \%$, vehicle control) or with apabetalone $(25 \mu \mathrm{M})$ for $24 \mathrm{~h}$. In stimulated conditions, monocytes were incubated with DMSO, IFN $\gamma(25 \mathrm{U} / \mathrm{ml})+\mathrm{DMSO}$ or 
IFN $\gamma+$ apabetalone $(25 \mu \mathrm{M})$ for $24 \mathrm{~h}$. Supernatants were collected from triplicate treatments, pooled and analysed using the Millipore Milliplex ${ }^{\circledR}$ Human Cytokine Array / Chemokine Array 42-Plex with IL-18 (HD42) (Eve Technologies, Calgary, AB) to quantify EGF, Eotaxin-1, FGF2, Flt-3L, Fractalkine, G-CSF, GM-CSF, GRO $\alpha$, IFN 2 , IFN $\gamma$, IL-1 $\alpha$, IL-1 $\beta$, IL-1RA, IL-2, IL-3, IL-4, IL-5, IL-6, IL-7, IL-8, IL-9, IL-10, IL-12 (p40), IL-12 (p70), IL-13, IL-15, IL-17A, IL-18, IP-10, MCP-1, MCP-3, MDC, MIP- $1 \alpha$, MIP- $1 \beta$, PDGF-AA, PDGF-AB/BB, RANTES, sCD40L, TGF $\alpha$, TNF $\alpha$, TNF $\beta$ and VEGF-A.

\section{ELISA}

Cytokine levels were measured in samples used for multianalyte immunoprofiling by commercially available enzyme-linked immunosorbent assay kits for MCP-1, IL- 8 and IL- $1 \beta$ according to the manufacturer's instructions (Invitrogen). High binding half area 96 well plates were used for these assays.

\section{Chromatin immunoprecipitation}

To assess BET protein chromatin occupancy, THP-1 cells were pre-treated with BET inhibitors for $1 \mathrm{~h}$ before addition of IFN $\gamma(25 \mathrm{U} / \mathrm{ml})$ for a $4 \mathrm{~h}$ co-incubation period. After cross-linking cells with formaldehyde, Active Motif Inc. (Carlsbad, CA) performed chromatin isolation and immunoprecipitation with BRD4 antibodies (Bethyl). Samples were processed in triplicate. Statistical significance was determined through 2-way ANOVA followed by Tukey's Multiple Comparison Test.

\section{Statistical analysis}

Differences in gene expression were determined to be statistically significant by comparing endogenous control-normalized raw counts (calculated by $\mathrm{nSolver}^{\mathrm{TM}}$ ) using a 2-way repeated measures ANOVA test followed by Tukey's multiple comparisons correction for withingroup comparisons, or Bonferroni's test for betweengroup comparisons (PRISM 8). Statistically significant differences in protein secretion were determined by comparing absolute concentrations (obtained by Milliplex ${ }^{\circledR}$ immunoprofiling). Percent change in gene expression was calculated versus each subject's DMSO-treated sample or IFN $\gamma$-treated sample and compared between cohorts with 2-way ANOVA followed by Tukey's test. Results are presented as mean or median values \pm SEM. $p$ value $\leq 0.05$ was considered statistically significant.

\section{Supplementary information}

Supplementary information accompanies this paper at https://doi. org/10.1186/s13148-020-00943-0.

Additional file 1-3. Additional file 1. Analysis of monocyte subpopulations in control (CTL) and DM2+CVD patients. Monocytes were classified as classical (CD14++CD16-), intermediate (CD14++CD16+) or non-classical (CD14+CD16+). Fluorescence was measured using a FACS CANTO II (BD) and analysed with FlowJo software. Additional file 2. Monocytes were stimulated ex vivo with IFNy $(1.5,3.12,6.25,12.5$ or $25 \mathrm{U} /$ $\mathrm{ml})$, apabetalone $(1.5,3.12,6.25,12.5$ or $25 \mu \mathrm{M})$, or a combination of both stimuli for $24 \mathrm{~h}$. Subsequently, cytotoxicity was determined by measuring the enzyme lactate dehydrogenase $(\mathrm{LDH})$ in the supernatant using the CytoTox $966^{\circledR}$ non-radioactive cytotoxicity assay (Promega). There was no difference between 'unstimulated' and 'stimulated' conditions, except for the positive control where $p<0.0001$. Statistics: One-way ANOVA with Dunnett's multiple comparisons test. Additional file 3. BRD4 mRNA expression is reduced by ex vivo treatment with apabetalone in DM2+CVD monocytes (4h ex vivo treatment, $25 \mu \mathrm{M}$ ). BRD4 expression was measured by real-time PCR and normalized to cyclophilin A (endogenous control). Statistics: Unpaired Student's t-test, ${ }^{* * * *}, p<0.0001$.

Additional file 4-7. Additional file 4. Apabetalone's gene targets in IPA ${ }^{\circledR}$ canonical pathways gene sets: Unstimulated control and DM2+CVD monocytes treated with apabetalone ex vivo. Additional file 5. Apabetalone's gene targets that converge on IPA ${ }^{\circledR}$ upstream regulators: unstimulated monocytes treated with apabetalone ex vivo. Additional file 6. Apabetalone's gene targets within IPA ${ }^{\circledR}$ canonical pathways: IFNY stimulated monocytes treated with apabetalone ex vivo. Additional file 7. Apabetalone's gene targets in IPA ${ }^{\circledR}$ upstream regulators gene sets: IFNy stimulated control and DM2+CVD patient monocytes treated with apabetalone ex vivo.

\section{Abbreviations}

BD: Bromodomain; BET: Bromodomain and extraterminal; BETi: BET inhibitor; CASP1: NLRP3 inflammasome-associated caspase 1 protease; CVD: Cardiovascular disease; DM2: Type 2 diabetes mellitus; FCAR: Fc region of IgA; GM-CSF: Granulocyte-macrophage colony stimulating factor; GRO: Growth-regulated oncogene; HDL: High-density lipoprotein; IFNY: Interferon gamma; IL: Interleukin; IL-1RA: Interleukin 1 receptor antagonist IL-1RA; IPA ${ }^{\circledR}$ : Ingenuity ${ }^{\circledR}$ Pathway Analysis; LDL: Low-density lipoprotein; MACE: Major acute cardiac event; MARCO: Macrophage receptor with collagenous structure; MCP: Monocyte chemoattractant protein; MS4A4A: Membrane-spanning 4-domains subfamily A member 4A; NF-kB: Nuclear factor $\mathrm{k}$-light-chain-enhancer of activated $B$ cells; PBMC: Peripheral blood mononuclear cells; PRR: Pattern recognition receptor; ROS: Reactive oxygen species; TLR: Toll-like receptor; TNF:Tumor necrosis factor; SF3A3: Splicing factor 3A subunit 3.

\section{Acknowledgements}

We would like to thank Resverlogix's lab members for intellectual input and manuscript review.

\section{Authors' contributions}

EK, NCWW, JOJ and MS conceived the project. EK, SW, BDR, ESGS, KED and MB designed the study. ESGS, JK and EK supervised the research. JK, KED, MV, MB, LF and SW collected, analysed and/or interpreted the data. BR managed the project and performed the statistical analysis. YK recruited patients. SW, SCS, EK, ESGS, KED and JK wrote and revised the manuscript. All authors read and approved the final manuscript.

\section{Funding}

This work was financially supported by Resverlogix Corp. and the Netherlands CardioVascular Research Initiative: the Dutch Heart Foundation, Dutch Federation of University Medical Centers, the Netherlands, Organization for Health Research and Development and the Royal Netherlands Academy of Sciences 
for the GENIUS-II project 'Generating the best evidence-based pharmaceutical targets for atherosclerosis-II' (CVON 2017-20). This work was furthermore financially supported by the Netherlands Organization for Scientific Research (VENI Grant from ZonMW; 91619098 to JK).

\section{Availability of data and materials}

All data generated or analysed during this study are included in this published article and its supplementary information files.

\section{Ethics approval and consent to participate}

The study protocol was approved by the medical ethical committee of the Amsterdam Medical Centre in Amsterdam, the Netherlands. Each subject provided written informed consent.

\section{Consent for publication}

Not applicable.

\section{Competing interests}

S.W., B.D.R., S.C.S, L.F., J.O.J., M.S., N.C.W.W. and E.K. are employed by Resverlogix Corp. \& hold company's shares and stock options. All other authors declare that they have no competing interests.

\section{Author details \\ ${ }^{1}$ Resverlogix Corp, 300-4820 Richard Road SW, Calgary, AB T3E 6L1, Canada. \\ ${ }^{2}$ Department of Experimental Vascular Medicine, Amsterdam Cardiovascular Sciences, Amsterdam UMC, University of Amsterdam, Meibergdreef 9, Amster- dam, The Netherlands. ${ }^{3}$ Department of Vascular Medicine, Amsterdam Cardio- vascular Sciences, Amsterdam UMC, University of Amsterdam, Meibergdreef 9, Amsterdam, The Netherlands.}

Received: 3 April 2020 Accepted: 7 October 2020

Published online: 11 November 2020

\section{References}

1. Einarson TR, Acs A, Ludwig C, Panton UH. Prevalence of cardiovascular disease in type 2 diabetes: a systematic literature review of scientific evidence from across the world in 2007-2017. Cardiovasc Diabetol. 2018;17:83.

2. Akash MS, Rehman K, Chen S. Role of inflammatory mechanisms in pathogenesis of type 2 diabetes mellitus. J Cell Biochem. 2013;114:525-31.

3. Ebtehaj S, Gruppen EG, Parvizi M, Tietge UJF, Dullaart RPF. The anti-inflammatory function of HDL is impaired in type 2 diabetes: role of hyperglycemia, paraoxonase-1 and low grade inflammation. Cardiovasc Diabetol. 2017;16:132.

4. Groh L, Keating ST, Joosten LAB, Netea MG, Riksen NP. Monocyte and macrophage immunometabolism in atherosclerosis. Semin Immunopathol. 2018:40:203-14.

5. Yuan T, Yang T, Chen H, Fu D, Hu Y, Wang J, et al. New insights into oxidative stress and inflammation during diabetes mellitus-accelerated atherosclerosis. Redox Biol. 2019;20:247-60.

6. Spranger J, Kroke A, Mohlig M, Hoffmann K, Bergmann MM, Ristow M, et al. Inflammatory cytokines and the risk to develop type 2 diabetes: results of the prospective population-based European Prospective Investigation into Cancer and Nutrition (EPIC)-Potsdam Study. Diabetes. 2003;52:812-7.

7. Amengual J, Barrett TJ. Monocytes and macrophages in atherogenesis. Curr Opin Lipidol. 2019;30:401-8.

8. Shirai T, Nazarewicz RR, Wallis BB, Yanes RE, Watanabe R, Hilhorst M, et al. The glycolytic enzyme PKM2 bridges metabolic and inflammatory dysfunction in coronary artery disease. J Exp Med. 2016;213:337-54.

9. Bekkering S, Stiekema LCA, Bernelot Moens S, Verweij SL, Novakovic B, Prange $\mathrm{K}$, et al. Treatment with statins does not revert trained immunity in patients with familial hypercholesterolemia. Cell Metab. 2019;30:1-2.

10. Bekkering S, van den Munckhof I, Nielen T, Lamfers E, Dinarello C, Rutten J, et al. Innate immune cell activation and epigenetic remodeling in symptomatic and asymptomatic atherosclerosis in humans in vivo. Atherosclerosis. 2016;254:228-36.
11. Christ A, Gunther P, Lauterbach MAR, Duewell P, Biswas D, Pelka K, et al. Western diet triggers NLRP3-dependent innate immune reprogramming. Cell. 2018;172:162-75.

12. Seijkens T, Hoeksema MA, Beckers L, Smeets E, Meiler S, Levels J, et al. Hypercholesterolemia-induced priming of hematopoietic stem and progenitor cells aggravates atherosclerosis. FASEB J. 2014;28:2202-13.

13. Mitroulis I, Ruppova K, Wang B, Chen LS, Grzybek M, Grinenko T, et al. Modulation of myelopoiesis progenitors is an integral component of trained immunity. Cell. 2018;172:147-61.

14. Neele AE, Van den Bossche J, Hoeksema MA, de Winther MP. Epigenetic pathways in macrophages emerge as novel targets in atherosclerosis. Eur J Pharmacol. 2015;763:79-89.

15. Cao Q, Wang X, Jia L, Mondal AK, Diallo A, Hawkins GA, et al. Inhibiting DNA methylation by 5-Aza-2'-deoxycytidine ameliorates atherosclerosis through suppressing macrophage inflammation. Endocrinology. 2014;155:4925-38.

16. Hoeksema MA, Gijbels MJ, Van den Bossche J, van der Velden S, Sijm A, Neele $A E$, et al. Targeting macrophage Histone deacetylase 3 stabilizes atherosclerotic lesions. EMBO Mol Med. 2014;6:1124-32.

17. Miao F, Chen Z, Zhang L, Wang J, Gao H, Wu X, et al. RNA-sequencing analysis of high glucose-treated monocytes reveals novel transcriptome signatures and associated epigenetic profiles. Physiol Genomics. 2013;45:287-99.

18. Miao F, Chen Z, Genuth S, Paterson A, Zhang L, Wu X, et al. Evaluating the role of epigenetic histone modifications in the metabolic memory of type 1 diabetes. Diabetes. 2014;63:1748-62.

19. Bekkering S, Quintin J, Joosten LA, van der Meer JW, Netea MG, Riksen NP. Oxidized low-density lipoprotein induces long-term pro-inflammatory cytokine production and foam cell formation via epigenetic reprogramming of monocytes. Arterioscler Thromb Vasc Biol. 2014;34:1731-8.

20. Taniguchi Y. The bromodomain and extra-terminal domain (BET) family: functional anatomy of BET paralogous proteins. Int J Mol Sci. 2016;17:1849.

21. Liu R, Zhong Y, Li X, Chen H, Jim B, Zhou MM, et al. Role of transcription factor acetylation in diabetic kidney disease. Diabetes. 2014;63:2440-53.

22. Zou Z, Huang B, Wu X, Zhang H, Qi J, Bradner J, et al. Brd4 maintains constitutively active NF-kappaB in cancer cells by binding to acetylated RelA. Oncogene. 2014;33:2395-404.

23. Brown JD, Lin CY, Duan Q, Griffin G, Federation A, Paranal RM, et al. NFkappaB directs dynamic super enhancer formation in inflammation and atherogenesis. Mol Cell. 2014;56:219-31.

24. Tian B, Yang J, Zhao Y, Ivanciuc T, Sun H, Garofalo RP, et al. BRD4 couples NF-kappaB/RelA with airway inflammation and the IRF-RIG-I amplification loop in respiratory syncytial virus infection. JVirol. 2017;91:e00007-17.

25. Patel MC, Debrosse M, Smith M, Dey A, Huynh W, Sarai N, et al. BRD4 coordinates recruitment of pause release factor P-TEFb and the pausing complex NELF/DSIF to regulate transcription elongation of interferonstimulated genes. Mol Cell Biol. 2013;33:2497-507.

26. Li Y, Liu M, Chen LF, Chen R. P-TEFb: Finding its ways to release promoterproximally paused RNA polymerase II. Transcription. 2018;9:88-94.

27. Huang B, Yang XD, Zhou MM, Ozato K, Chen LF. Brd4 coactivates transcriptional activation of NF-kappaB via specific binding to acetylated RelA. Mol Cell Biol. 2009;29:1375-87.

28. Das S, Senapati P, Chen Z, Reddy MA, Ganguly R, Lanting L, et al. Regulation of angiotensin II actions by enhancers and super-enhancers in vascular smooth muscle cells. Nat Commun. 2017;8:1467.

29. Dey A, Yang W, Gegonne A, Nishiyama A, Pan R, Yagi R, et al. BRD4 directs hematopoietic stem cell development and modulates macrophage inflammatory responses. EMBO J. 2019;38:e100293.

30. Nicodeme E, Jeffrey KL, Schaefer U, Beinke S, Dewell S, Chung CW, et al. Suppression of inflammation by a synthetic histone mimic. Nature. 2010:468:1119-23.

31. Picaud S, Wells C, Felletar I, Brotherton D, Martin S, Savitsky P, et al. RVX208, an inhibitor of BET transcriptional regulators with selectivity for the second bromodomain. Proc Natl Acad Sci U S A. 2013;110:19754-9.

32. McLure KG, Gesner EM, Tsujikawa L, Kharenko OA, Attwell S, Campeau E, et al. RVX-208, an inducer of ApoA-I in humans, is a BET bromodomain antagonist. PLOS ONE. 2013;8:e83190. 
33. Wang Q, Li Y, Xu J, Wang Y, Leung EL, Liu L, et al. Selective inhibition mechanism of RVX-208 to the second bromodomain of bromo and extraterminal proteins: insight from microsecond molecular dynamics simulations. Sci Rep. 2017;7:8857.

34. Tsujikawa LM, Fu L, Das S, Halliday C, Rakai BD, Stotz SC, et al. Apabetalone (RVX-208) reduces vascular inflammation in vitro and in CVD patients by a BET-dependent epigenetic mechanism. Clin Epigenet. 2019;11:102.

35. Jahagirdar R, Zhang H, Azhar S, Tobin J, Attwell S, Yu R, et al. A novel BET bromodomain inhibitor, RVX-208, shows reduction of atherosclerosis in hyperlipidemic ApoE deficient mice. Atherosclerosis. 2014;236:91-100.

36. Gilham D, Tsujikawa LM, Sarsons CD, Halliday C, Wasiak S, Stotz SC, et al. Apabetalone downregulates factors and pathways associated with vascular calcification. Atherosclerosis. 2019;280:75-84.

37. Boshuizen MC, de Winther MP. Interferons as essential modulators of atherosclerosis. Arterioscler Thromb Vasc Biol. 2015;35:1579-88.

38. Dasu MR, Devaraj S, Park S, Jialal I. Increased toll-like receptor (TLR) activation and TLR ligands in recently diagnosed type 2 diabetic subjects. Diabetes Care. 2010;33:861-8.

39. Devaraj S, Dasu MR, Rockwood J, Winter W, Griffen SC, Jialal I. Increased toll-like receptor (TLR) 2 and TLR4 expression in monocytes from patients with type 1 diabetes: further evidence of a pro-inflammatory state. J Clin Endocrinol Metab. 2008;93:578-83.

40. Jialal I, Huet BA, Kaur H, Chien A, Devaraj S. Increased toll-like receptor activity in patients with metabolic syndrome. Diabetes Care. 2012;35:900-4

41. Okada K, Arai S, Itoh H, Adachi S, Hayashida M, Nakase H, et al. CD68 on rat macrophages binds tightly to S100A8 and S100A9 and helps to regulate the cells'immune functions. J Leukoc Biol. 2016;100:1093-104.

42. Han X, Boisvert WA. Interleukin-10 protects against atherosclerosis by modulating multiple atherogenic macrophage function. Thromb Haemost. 2015:113:505-12.

43. Yin L, Yong-Bo P, Meng-Fei Y, Weiwei C, Ping Z, Lu X, et al. Mice lacking myotubularin-related protein 14 show accelerated high-fat diet-induced lipid accumulation and inflammation. J Physiol Biochem. 2017;73:17-28.

44. Liebermann DA, Gregory B, Hoffman B. AP-1 (Fos/Jun) transcription factors in hematopoietic differentiation and apoptosis. Int J Oncol. 1998:12:685-700.

45. Chan CH, Fang C, Yarilina A, Prinjha RK, Qiao Y, Ivashkiv LB. BET bromodomain inhibition suppresses transcriptional responses to cytokine-JakSTAT signaling in a gene-specific manner in human monocytes. Eur J Immunol. 2015;45:287-97.

46. Most J, Schwaeble W, Drach J, Sommerauer A, Dierich MP. Regulation of the expression of ICAM-1 on human monocytes and monocytic tumor cell lines. J Immunol. 1992;148:1635-42.

47. Qi XF, Kim DH, Yoon YS, Jin D, Huang XZ, Li JH, et al. Essential involvement of cross-talk between IFN-gamma and TNF-alpha in CXCL10 production in human THP-1 monocytes. J Cell Physiol. 2009:220:690-7.

48. Gibbons HR, Mi DJ, Farley VM, Esmond T, Kaood MB, Aune TM. Bromodomain inhibitor JQ1 reversibly blocks IFN-gamma production. Sci Rep. 2019;9:10280

49. Marie IJ, Chang HM, Levy DE. HDAC stimulates gene expression through BRD4 availability in response to IFN and in interferonopathies. J Exp Med. 2018:215:3194-212

50. He Y, Hara H, Nunez G. Mechanism and regulation of NLRP3 inflammasome activation. Trends Biochem Sci. 2016:41:1012-21.

51. Lin J, Kakkar V, Lu X. Essential roles of toll-like receptors in atherosclerosis. Curr Med Chem. 2016;23:431-54.

52. Foldes G, von Haehling S, Okonko DO, Jankowska EA, Poole-Wilson PA, Anker SD. Fluvastatin reduces increased blood monocyte toll-like receptor 4 expression in whole blood from patients with chronic heart failure. Int J Cardiol. 2008;124:80-5.

53. Kong F, Ye B, Lin L, Cai X, Huang W, Huang Z. Atorvastatin suppresses NLRP3 inflammasome activation via TLR4/MyD88/NF-kappaB signaling in PMA-stimulated THP-1 monocytes. Biomed Pharmacother. 2016;82:167-72

54. Methe H, Kim JO, Kofler S, Nabauer M, Weis M. Statins decrease toll-like receptor 4 expression and downstream signaling in human CD14+ monocytes. Arterioscler Thromb Vasc Biol. 2005;25:1439-45.

55. Connolly M, Veale DJ, Fearon U. Acute serum amyloid A regulates cytoskeletal rearrangement, cell matrix interactions and promotes cell migration in rheumatoid arthritis. Ann Rheum Dis. 2011;70:1296-303.
56. Hansen IS, Hoepel W, Zaat SAJ, Baeten DLP, den Dunnen J. Serum IgA immune complexes promote pro-inflammatory cytokine production by human macrophages, monocytes, and kupffer cells through FcalphaRlTLR cross-talk. J Immunol. 2017;199:4124-31.

57. Ferreri NR, Howland WC, Spiegelberg HL. Release of leukotrienes C4 and B4 and prostaglandin E2 from human monocytes stimulated with aggregated lgG, IgA, and IgE. J Immunol. 1986;136:4188-93.

58. Patry C, Herbelin A, Lehuen A, Bach JF, Monteiro RC. FC alpha receptors mediate release of tumour necrosis factor-alpha and interleukin-6 by human monocytes following receptor aggregation. Immunology. 1995;86:1-5

59. Cimini FA, Barchetta I, Porzia A, Mainiero F, Costantino C, Bertoccini $L$, et al. Circulating IL-8 levels are increased in patients with type 2 diabetes and associated with worse inflammatory and cardiometabolic profile. Acta Diabetol. 2017;54:961-7

60. Sajadi SM, Khoramdelazad H, Hassanshahi G, Rafatpanah H, Hosseini J, Mahmoodi M, et al. Plasma levels of CXCL1 (GRO-alpha) and CXCL10 (IP-10) are elevated in type 2 diabetic patients: evidence for the involvement of inflammation and angiogenesis/angiostasis in this disease state. Clin Lab. 2013;59:133-7.

61. de Oliveira RT, Mamoni RL, Souza JR, Fernandes JL, Rios FJ, Gidlund M, et al. Differential expression of cytokines, chemokines and chemokine receptors in patients with coronary artery disease. Int J Cardiol. 2009;136:17-26.

62. Papadopoulou C, Corrigall V, Taylor PR, Poston RN. The role of the chemokines MCP-1, GRO-alpha, IL-8 and their receptors in the adhesion of monocytic cells to human atherosclerotic plaques. Cytokine. 2008;43:181-6.

63. Meniailo ME, Malashchenko VV, Shmarov VA, Gazatova ND, Melashchenko OB, Goncharov AG, et al. Interleukin-8 favors pro-inflammatory activity of human monocytes/macrophages. Int Immunopharmacol. 2018;56:217-21.

64. Gerszten RE, Garcia-Zepeda EA, Lim YC, Yoshida M, Ding HA, Gimbrone MA Jr, et al. MCP-1 and IL-8 trigger firm adhesion of monocytes to vascular endothelium under flow conditions. Nature. 1999;398:718-23.

65. Takahashi M, Ikeda U, Masuyama J, Kitagawa S, Kasahara T, Shimpo $\mathrm{M}$, et al. Monocyte-endothelial cell interaction induces expression of adhesion molecules on human umbilical cord endothelial cells. Cardiovasc Res. 1996;32:422-9.

66. Kamari Y, Shaish A, Shemesh S, Vax E, Grosskopf I, Dotan S, et al. Reduced atherosclerosis and inflammatory cytokines in apolipoprotein-E-deficient mice lacking bone marrow-derived interleukin-1alpha. Biochem Biophys Res Commun. 2011;405:197-203.

67. Lurier EB, Dalton D, Dampier W, Raman P, Nassiri S, Ferraro NM, et al. Transcriptome analysis of IL-10-stimulated (M2C) macrophages by next-generation sequencing. Immunobiology. 2017;222:847-56.

68. Mattiola I, Tomay F, De Pizzol M, Silva-Gomes R, Savino B, Gulic T, et al. The macrophage tetraspan MS4A4A enhances dectin-1-dependent NK cell-mediated resistance to metastasis. Nat Immunol. 2019;20:1012-22.

69. De Arras L, Alper S. Limiting of the innate immune response by SF3Adependent control of MyD88 alternative mRNA splicing. PLoS Genet. 2013;9:e1003855

70. Barrat FJ, Crow MK, Ivashkiv LB. Interferon target-gene expression and epigenomic signatures in health and disease. Nat Immunol. 2019;20:1574-83.

71. Das S, Reddy MA, Senapati P, Stapleton K, Lanting L, Wang M, et al. Diabetes mellitus-induced long noncoding RNA Dnm3os regulates macrophage functions and inflammation via nuclear mechanisms. Arterioscler Thromb Vasc Biol. 2018;38:1806-20.

72. Li Y, Reddy MA, Miao F, Shanmugam N, Yee JK, Hawkins D, et al. Role of the histone $\mathrm{H} 3$ lysine 4 methyltransferase, SET7/9, in the regulation of NF-kappaB-dependent inflammatory genes. Relevance to diabetes and inflammation. J Biol Chem. 2008;283:26771-81.

73. Greissel A, Culmes M, Burgkart R, Zimmermann A, Eckstein $\mathrm{HH}$, Zernecke A, et al. Histone acetylation and methylation significantly change with severity of atherosclerosis in human carotid plaques. Cardiovasc Pathol. 2016;25:79-86.

74. van der Kroef M, Castellucci M, Mokry M, Cossu M, Garonzi M, BossiniCastillo LM, et al. Histone modifications underlie monocyte dysregulation in patients with systemic sclerosis, underlining the treatment potential of epigenetic targeting. Ann Rheum Dis. 2019;78:529-38. 
75. Kanter JE, Hsu CC, Bornfeldt KE. Monocytes and macrophages as protagonists in vascular complications of diabetes. Front Cardiovasc Med. 2020;7:10.

76. Swirski FK, Libby P, Aikawa E, Alcaide P, Luscinskas FW, Weissleder R, et al. Ly-6Chi monocytes dominate hypercholesterolemia-associated monocytosis and give rise to macrophages in atheromata. J Clin Invest. 2007;117:195-205.

77. Parathath S, Grauer L, Huang LS, Sanson M, Distel E, Goldberg IJ, et al. Diabetes adversely affects macrophages during atherosclerotic plaque regression in mice. Diabetes. 2011;60:1759-69.

78. Nagareddy PR, Murphy AJ, Stirzaker RA, Hu Y, Yu S, Miller RG, et al. Hyperglycemia promotes myelopoiesis and impairs the resolution of atherosclerosis. Cell Metab. 2013;17:695-708.

79. Szentes V, Gazdag M, Szokodi I, Dezsi CA. The role of CXCR3 and associated chemokines in the development of atherosclerosis and during myocardial infarction. Front Immunol. 2018;9:1932.

80. Ucla C, Roux-Lombard P, Fey S, Dayer JM, Mach B. Interferon gamma drastically modifies the regulation of interleukin 1 genes by endotoxin in U937 cells. J Clin Invest. 1990;85:185-91.

81. Jiang X, Wang F, Wang Y, Gistera A, Roy J, Paulsson-Berne G, et al. Inflammasome-driven interleukin-1alpha and interleukin-1 beta production in atherosclerotic plaques relates to hyperlipidemia and plaque complexity. JACC Basic Transl Sci. 2019;4:304-17.

82. Ridker PM, Everett BM, Thuren T, MacFadyen JG, Chang WH, Ballantyne $C$, et al. Antiinflammatory therapy with canakinumab for atherosclerotic disease. N Engl J Med. 2017;377:1119-31.
83. Nicholls SJ, Ray KK, Johansson JO, Gordon A, Sweeney M, Halliday C, et al. Selective BET protein inhibition with apabetalone and cardiovascular events: a pooled analysis of trials in patients with coronary artery disease. Am J Cardiovasc Drugs. 2018;18:109-15.

84. Ray KK, Nicholls SJ, Buhr KA, Ginsberg HN, Johansson JO, Kalantar-Zadeh $K$, et al. Effect of apabetalone added to standard therapy on major adverse cardiovascular events in patients with recent acute coronary syndrome and type 2 diabetes: a randomized clinical trial. JAMA. 2020;323(16):1565-73.

85. Ray KK, Nicholls SJ, Ginsberg HD, Johansson JO, Kalantar-Zadeh K, Kulikowski E, et al. Effect of selective BET protein inhibitor apabetalone on cardiovascular outcomes in patients with acute coronary syndrome and diabetes: rationale, design, and baseline characteristics of the BETonMACE trial. Am Heart J. 2019;217:72-83.

86. Schnitzler JG, Bernelot Moens SJ, Tiessens F, Bakker GJ, Dallinga-Thie GM, Groen AK, et al. Nile red quantifier: a novel and quantitative tool to study lipid accumulation in patient-derived circulating monocytes using confocal microscopy. J Lipid Res. 2017;58:2210-9.

\section{Publisher's Note}

Springer Nature remains neutral with regard to jurisdictional claims in published maps and institutional affiliations.
Ready to submit your research? Choose BMC and benefit from:

- fast, convenient online submission

- thorough peer review by experienced researchers in your field

- rapid publication on acceptance

- support for research data, including large and complex data types

- gold Open Access which fosters wider collaboration and increased citations

- maximum visibility for your research: over 100M website views per year

At BMC, research is always in progress.

Learn more biomedcentral.com/submissions 